\title{
TAL PERFORMANCE AND MISSION ANALYSIS IN A CDL CAPACITOR POWERED DIRECT-DRIVE CONFIGURATION
}

\author{
Ivana Hrbud, M. Frank Rose', Steve R. Oleson", Rhonald M. Jenkins ${ }^{B}$ \\ 'Propulsion Research Center, NASA Marshall Space Flight Center, Huntsville, AL \\ ${ }^{+}$Space Science Laboratories, NASA Marshall Space Flight Center, Huntsville. AL \\ 'NYMA Inc., 2001 Aerospace Parkway, Brook Park, OH \\ ${ }^{B}$ Department of Aerospace Engineering, 211 Aerospace BIdg., Auburn University, AL
}

\begin{abstract}
The goals of this research are (1) to prove the concept feasibility of a direct-drive electric propulsion system, and (2) to evaluate the performance and characteristics of a Russian TAL (Thruster with Anode Layer) operating in a long-pulse mode, powered by a capacitor-based power source developed at Space Power Institute. The TAL, designated D-55, is characterized by an external acceleration zone and is powered by a unique chemical double layer (CDL) capacitor bank with a capacitance of $4 \mathrm{~F}$ at a charge voltage of $400 \mathrm{~V}$. Performance testing of this power supply on the TAL was conducted at NASA Lewis Research Center in Cleveland, OH. Direct thrust measurements of the TAL were obtained at CDL power levels ranging from 450 to $1750 \mathrm{~W}$. The specific impulse encompassed a range from $1150 \mathrm{~s}$ to $2200 \mathrm{~s}$, yielding thruster system efficiencies between 50 and $60 \%$. Preliminary mission analysis of the CDL direct-drive concept and other electric propulsion options was performed for the ORACLE spacecraft in $6 \mathrm{am} / 6 \mathrm{pm}$ and $12 \mathrm{am} / 12 \mathrm{pm}, 300 \mathrm{~km}$ sun-synchronous orbits. The direct-drive option was competitive with the other systems by increasing available net mass between 5 and $42 \%$ and reducing two-year system wet mass between 18 and 63\%. Overall, the electric propulsion power requirements for the satellite solar array were reduced between 57 and $91 \%$ depending on the orbit evaluated. The direct-drive, CDL capacitor-based concept in electric propulsion thus promises to be a highly-efficient, viable alternative for satellite operations in specific near-Earth missions.
\end{abstract}

\footnotetext{
- IPA Fellow with NASA MSFC, Member AIAA

- Director Space Sciences laboratories, Associate Fellow AIA

: Senior Research Engineer, Member AlA

Bssociate Professor, Acrospace Enginering 



\section{NOMENCLATURE}

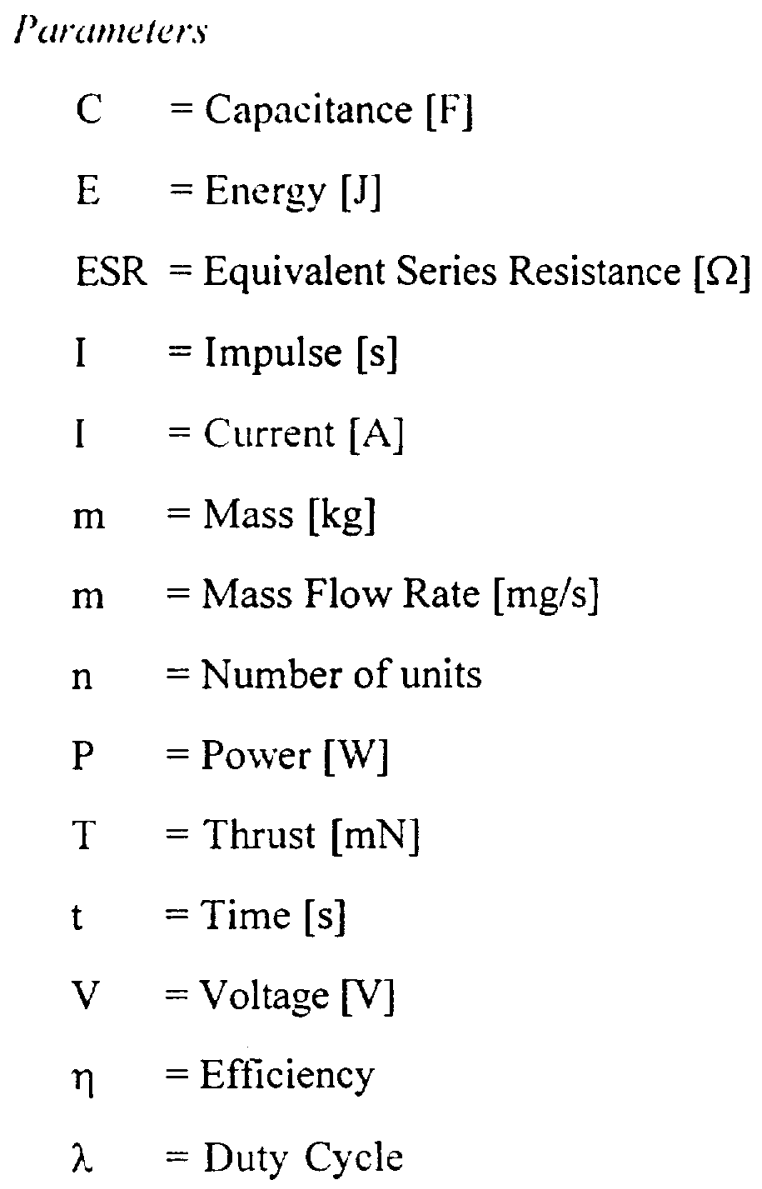

\section{Indices}

$$
\begin{aligned}
& \mathrm{a}=\text { anode } \\
& \mathrm{b}=\text { burn } \\
& \mathrm{id}=\text { initial discharge } \\
& \mathrm{T}=\text { thruster } \\
& \mathrm{a} \quad=\text { anode plus cathode } \\
& \mathrm{EP}=\text { elcctric propulsion } \\
& \mathrm{sp}=\text { specific } \\
& \mathrm{PPU}=\text { power processing unit }
\end{aligned}
$$




\section{INTRODUCTION}

Both industry and government agencies seck out new technologies to reduce prevailing high launch costs of existing and future space missions. In 1994, NASA initiated the New Millennium Program' to identify, promote, and to fund research and development of specific advanced technologies for advanced spacecraft via partnership of academia, industry, and government. For

its space and Earth exploration in the 21 st century, NASA proposes the frequent launch of affordable missions to be accomplished by small, low-cost spacecraft. For space commercialization, weight reduction of the power source and propulsion system is required. Since some future spacecraft power systems will be severely power limited, ${ }^{1}$ the use of highpower thrusters is questionable; however, pulsed mode operation of chemical double layer (CDL) capacitors in conjunction with a Hall thruster will allow 'seconds' of high-power, high-efficiency propulsion. The pulse repetition rate will determine the average power necessary to perform the desired maneuver. This allows small, low-power satellites to employ the advantages of highpower, high-efficiency thrusters without producing excessive demand on the spacecraft's power train. A power supply consisting of CDL capacitors is certainly a good candidate for meeting future specifications in pulsed electric propulsion.

The direct-drive power option (Figure 1) for electric propulsion combining high-power, highefficiency thrusters and innovative energy storage in CDL capacitors as used in this research was first proposed by Rose. ${ }^{2}$ Preliminary results showed that mass and volume of the energy storage bank could be cut by a factor of three when using state-of-art CDL capacitor technology. In addition, a $30 \%$ reduction in overall system mass by driving the SPT-100 directly from the solar array bus was supported by Hamley. ${ }^{3}$

\section{CAPACITOR TECHNOLOGY}

\section{Operational Principle}

The most basic configuration of a capacitor is two conduction plates or electrodes separated by an insulator or a dielectric. In 1879, Helmholiz discovered that the interface between a conductor and a liçuid electrolyte formed a layer capable of storing charge." Negative and 
positive electric charges form on the boundary between the solid aclivated carbon particles and the liquid electrolyte. The boundary area between these charges is the electrical double layer, which is illustrated in Figure 2.

Furthermore, Figure 3 shows the principal structure of a CDL capacitor. The electrode of a unit cell is made of activated carbon particles or fibers with large surface area. The electrode is bonded on one side with a thin metal foil (e.g. aluminum, gold, etc.) that functions as the current collector and the entire electrode is impregnated with an aqueous or organic electrolyte solution.

Aqueous electrolytes (e.g. potassium hydroxide or sulfuric acid) offer high power densities and low resistances: however, such chemical solutions are corrosive and pose limitations in applications with long life requirements. Organic electrolytes (e.g. propylene carbonate), on the other hand, achieve higher energy densities than aqueous electrolytes since they can be operated at higher voltages. However, high internal resistances from organic electrolytes limit the application range of these capacitors. ${ }^{5}$ The voltage limitation is on the order of $1 \mathrm{~V}$ for aqueous electrolytes and about $3 \mathrm{~V}$ for organic electrolytes. These limits are imposed due to the nature of the electrolytes and the potential needed to decompose them into their constituents. A parametric study of CDL capacitors is discussed in detail by Rose. ${ }^{5}$ A separator with high insulation properties for electrons, but permitting ionic conduction is used between two electrodes.

\section{Comparison and Application Advantages}

In the past, batteries and electrolytic capacitors have dominated energy storage systems in pulsed applications. Although batteries possess high energy densities relative to CDL capacitors, they suffer from low power densities and have a poor charge-discharge cycle ability. Electrolytic capacitors achieve moderately high energy and power densities, but are sensitive to polarity, thermal cffects, and discharge rate. CDL capacitors have energy densities five times those of electrolytic capacitors and their power density is at least an order of magnitude higher than that of batteries. ${ }^{6,7}$ CDL capacitors outperform conventional rechargeable batteries in the 
number of charge-discharge cycles reaching up to 600,000 cycles with minimal degradation, even if the charge voltage is $30 \%$ higher than the manufacturer's specifications."

Although CDL capacitors are low voltage devices, high voltage applications can be achieved

with appropriate circuit design. Small satellites with moderate power bus voltages can achicve high capacitor charge voltages in excess of $300 \mathrm{~V}$ using modern solar array designs ${ }^{9}$ and an appropriate switching network. With the use of CDL capacitors, the spacecraft's power system exhibits a low average power demand for charging. The capacitance is sufficient to allow the power required for the Hall thrusters on board the satellite to be readily available following brief recharge periods. Since CDL capacitors can be fabricated in any desired shape and form, their superior volume-to-mass ratio has great potential in meeting the future packing and subsystem integration needs of satellite manufacturers. Table 1 summarizes available power storage technologies and their characteristics for space applications.

\section{HALL-ION THRUSTER RESEARCH}

There have been extensive research efforts on Hall thrusters with closed electron drift in both the United States ${ }^{10,11}$ and Russia ${ }^{12}$ since the early 1960's. The two varieties of this thruster concept are the thruster with anode layer (TAL) and the stationary plasma thruster (SPT). Although, research on Hall thrusters declined in the U.S. ${ }^{13,14}$ due to low thrust efficiencies, the unique performance capabilities of Russian thruster technology sparked interest among western electric propulsion researchers in the early 1990's. Various programs sponsored by BMDO (Ballistic Missile Defense Organization) and conducted at NASA Lewis Research Center and JPL evaluated and characterized the Russian thruster technology according to U.S. spacecraft mission requirements. ${ }^{15,16}$ Under the same programs a power processing unit (PPU) with an efficiency of $93 \%$ was developed to conduct performance and integration tests ${ }^{17}$ with the Russian thrusters. TAL and SPT thrustors achieved efficiencies of 50\% and an average specific impulse of $1600 \mathrm{~s}$ while operating at a nominal power level of $1300 \mathrm{~W}$ with a discharge voltage of $300 \mathrm{~V}$. Brophy also compared the SPI with arcjets and conventional ion thrusters, and found that the SPT thrusters exhibit several faromble chameteristics between specilic impulses of 1000 and $2000 \mathrm{~s}$. 
This is the specilic impulse range required for electric thruster applications for LEO missions, orbit raising and NSSK (north/south station keeping). ${ }^{18}$ To simulate typical mission applications of commercial communication satellites, endurance tests were performed combining extremely long operation times and thousands of on'off cycles. ${ }^{19.20}$ Even after the endurance test accumulated 4,165 hours of operation and 5,000 on/off cycles, the Russian SPT-100 was reported to have minimal degradation in efficiency. ${ }^{21}$ The lifetime-limiting factor, however, was found to be the erosion of thruster components. ${ }^{21 \cdot 22}$ In addition to the aforementioned research, one and two dimensional numerical flow field simulations of Hall thrusters have been performed to better understand acceleration processes ${ }^{23}$, and thus predict thruster performance. ${ }^{24}$

\section{EXPERIMENTAL APPARATUS AND PROCEDURE}

\section{Capacitor Power Source}

The CDL capacitor power source for the research consisted of the primary energy storage units (capacitor bank), charging/discharging power supply, and associated circuitry. The capacitor bank was designed and individual units configured to meet the specifications of the TAL. Each individual CDL capacitor unit was manufactured by Panasonic and rated for $470 \mathrm{~F}$ at a nominal operating voltage of $2.3 \mathrm{~V}$. In a simple test set-up, individual capacitor uniț were tested according their equivalent series resistance (ESR) and capacitance at a charge voltage of 3 $\mathrm{V}^{25}$ The capacitor bank consisted of 135 units wired in series which were distributed on three arrays of 45 units each. Based on an average unit capacitance of $540 \mathrm{~F}$, the total capacitance of the bank was $4 \mathrm{~F}$ and the designed operating voltage was not to exceed $400 \mathrm{~V}$. This resulted in an overall energy storage capacity of $320 \mathrm{~kJ}$ and a total bank ESR of approximately $800 \mathrm{~m} \Omega$ (resulting from an average unit ESR of $6 \mathrm{~m} \Omega$ ). The charging/discharging power supply was specifically designed to quickly ( -5 min.) charge the CDI capacitor bank to a maximum voltage of $400 \mathrm{~V}$ and included power clictronics to facilitate controlled, direct discharging of the stored energy into the TAL. To climinate special input power requirements, the power supply was designed for a residential $120 \mathrm{VAC} 15$ A receptacle. Figure 3 shows the chargingdischarging power supply and the CDI, capacitor bank. ${ }^{25}$

6

Americun lutime of Aeromuties and Astminutes 


\section{Thruster with Anode Layer}

Developed at the Central Research Institute of Machine Building (TsNIIMASH), the TAL is still a laboratory device, while its relative, the SPT has accumulated an impressive flight history. The TAL model D-55 is designed for a power range between 1000 and $2000 \mathrm{~W}$ utilizing xenon as propellant. The model classification D-55 signifies the inner diameter, in millimeters, of the annular discharge chamber. Previous investigations ${ }^{20,26}$ report a specific impulse of $1600 \mathrm{~s}$ and an efficiency of $48 \%$ at a nominal operating power level of $1300 \mathrm{~W}$ and a discharge voltage of $300 \mathrm{~V}$. The design and performance of the TAL's hollow cathode used in this research resulted from the NASA plasma contactor program for the Space Station, ${ }^{27}$ which is an outgrowth of NASA's technology development effort for ion thruster systems. The principle of operation of the thruster and hollow cathode are discussed elsewhere. ${ }^{28}$

\section{Facility}

Tests to prove the direct-drive concept, powering a Hall-ion thruster with a CDL capacitor bank, were performed at NASA Lewis Research Center in Cleveland, Ohio, under a Space Act Agreement (SAA). Performance testing of the TAL/D-55 was conducted on a testbed which had been previously used exclusively for electric propulsion testing and research. .The stainless steel vacuum chamber is $1.5 \mathrm{~m}$ in diameter and $4.6 \mathrm{~m}$ in length and is equipped with four oil diffusion pumps rated at a pumping speed of $30,000 \mathrm{l} / \mathrm{s}$ each. The thruster ${ }^{26,28}$ was mounted on an inverted pendulum-type thrust $\operatorname{stand}^{29}$ which positioned the thruster along the vacuum chamber centerline. Thruster subsystems such as keeper, heater, and magnets were each powered by isolated power supplies. ${ }^{30}$ The thruster was operated using xenon as propellant gas while the anode and cathode propellant flow rates were regulated by $100 \mathrm{sccm}$ full-scale and $20 \mathrm{sccm}$ fullscale thermal-conductivity flow controllers, respectively. A constant volume technique was applied for the calibration of the controllers. ${ }^{25,26}$ 


\section{Instrumentation and Data Acquisition}

Computer automated data acquisition recorded discharge voltage, discharge current, and thrust stand deflection using a Macintosh Ilci and LabVIEWTM software. ${ }^{25}$ Discharge voltage signals were provided by a voltage divider inside the charging/discharging power supply which reflected the discharge voltage between the anode and cathode inputs. A Hall effect current probe supplied a voltage signal for measuring the discharge current. The thrust stand deflection was measured with a linear variable differential transformer ${ }^{29}$ whose signals were recorded by a strip chart recorder as a function of time. This plotter had a set of signal output channels which supplied an analog voltage signal for the computer. All input voltage signals to the computer were conditioned with voltage isolating modules and were processed, calibrated, and displayed using LabVIEWTM software. In addition, the discharge voltage and current waveforms were recorded with a TEKTRONIX ${ }^{\mathrm{TM}}$ digitizing oscilloscope which featured data storage and output to an $\mathrm{x}, \mathrm{y}$-plotter. Two isolated digital multimeters having an input impedance of $10 \mathrm{M} \Omega$ measured discharge current and cathode-to-ground voltage to provide instant, real-time measurements to the thruster operator. Vacuum chamber pressures were measured at two locations using ionization gauges.

\section{Experimental Procedure}

Direct-drive system testing of CDL capacitor bank and TAL was conducted under the supervision and assistance of NASA Lewis engineers and technicians. Calibration of the thrust stand was performed in-situ before and after test runs by loading the apparatus with precisely calibrated weights. The anode/cathode propellant flows were turned off cluring the calibration procedure, and the thruster's magnetic fields had no affect on thrust stand calibration or actual thrust measurements. ${ }^{1620}$ The TAL, subsystem power supplies for imei magnet $(7.5 \mathrm{~V} / 4.2 \mathrm{~A})$. outer magnets $(3.5 \mathrm{~V} / 1 \mathrm{~A})$, kecper $(10.3 \mathrm{~V} / 0.35 \mathrm{~A})$, and heater $(10.5 \mathrm{~V} / 8 \mathrm{~A})$ were adjusted to specific values and were not changed during the entire testing process. Xenon flow rates through the anode and cathode were adjusted by a pair of thermal-conductivity flow controllers. The propellant llow rate through the cathode was set to $0.59 \mathrm{mg} / \mathrm{s}$ and was held constant throughout 
the testing. The anode propellant how rate ranged from 3 to 4.63 mg's and test data was recorded in increments of $0.25 \mathrm{mg} / \mathrm{s}$. A total of seven test runs were performed at an initial discharge voltage of $400 \mathrm{~V}$ running each anode mass flow rate setting twice to substantiate and verify results. In addition, four anode mass flow rates were selected at which the thruster was run from an initial discharge voltage of $300 \mathrm{~V}$ to evaluate performance characteristics and verifying repeatability at lower voltage. The main energy provided for the discharge between the anode and cathode was stored in the CDL capacitor bank. The current through the thruster, and thus the discharge power rate, was controlled by the anode propellant mass flow rate. For the anode flow rates ranging from 3 to $4.63 \mathrm{mg} / \mathrm{s}$, this translated into initial discharge currents varying from 2.7 to $4.4 \mathrm{~A}$. The inrush current in the start-up sequence was limited by a $10-\Omega$ ballast resistor which was shorted by a time delay relay $500 \mathrm{~ms}$ into the test cycle. When the discharge voltage from the CDL capacitor bank reached $150 \mathrm{~V}$, the bank was taken off-line, thus completing

the test cycle. The CDL capacitor bank was then recharged for the next test cycle. ${ }^{25,28}$

\section{RESULTS}

Table 2 summarizes experimental results for important performance characteristics as a function of anode mass flow rate at both $V_{i d}=400 \mathrm{~V}$ and $V_{i d}=300 \mathrm{~V}$. Parameters such as voltage, current, and thrust were measured, while power, specific impulse, and efficiency were calculated. Performance parameters are time dependent, since acceleration voltage is a function of time and decreases from either $400 \mathrm{~V}$ or $300 \mathrm{~V}$ to $150 \mathrm{~V}$. Due to the time-dependent nature of the expcriments, the table provides the initial and final values of each performance characteristic, and does not imply lincarity. Specific impulse and efticiency were calculated using both anode mass flow only and total mass flow rates (anode plus cathode flow).

A qualitative comparison ${ }^{25}$ of the results of this study with results reported by Sankovict showed equivalent performance characteristies and trends; hovever, diflerences in the experimental set-up (i.e. steady-shate versus lung pulse operation, vacum chanber) and, more importantly, the use of different cathode techologies do not allow a quantitative comparison of the hos studies. 
Figure 4 shows the voltage as a function of time and anode mass flow rate. This voltage is analogous to both the discharge voltage of the CDL capacitor bank and the aceelerating voltage between anode and cathode of the thruster. The pulse length depends on anode mass flow rate (i.e. current) and initial discharge voltage (i.e. stored energy). For the anode mass flow rate $\mathrm{m}_{\mathrm{a}}=4.57 \mathrm{mg} / \mathrm{s}$, all three test runs are identical and the pulse duration is $210 \mathrm{~s}(3.5 \mathrm{~min}$.). The two test run voltages at $m_{a}=3.29 \mathrm{mg} / \mathrm{s}$ are slightly apart, since the initial voltage of $T / 2 \mathrm{a}$ was higher $\left(V_{\text {id }, T / 2 d}=407 \mathrm{~V}\right)$ and consequently, the stored cnergy in the CDL capacitor bank was higher. The time required to drop from initial to final conditions is $326 \mathrm{~s}(5.43 \mathrm{~min}$.) for $\mathrm{T} / 2 \mathrm{a}$ and $314 \mathrm{~s}$ ( 5.27 min.) for $T / 2 b$. The rate at which the energy stored in the CDL capacitor bank dissipates is controlled by the current and represented by the slope of the voltage waveforms. After the end of each test run, which was terminated at about $150 \mathrm{~V}$ (as recommended by Sankovic), the energy stored in the CDL capacitor bank decreased to about $14 \%$ of its initial value at $400 \mathrm{~V}(320 \mathrm{~kJ})$.

Figure 5 shows current as a function of time and anode mass flow rates. The discharge current in TAL operation is controlled by throttling the anode mass flow rate independent of constant voltage input or decaying voltage input. As reported in Ref. 25 and 26 , the discharge current is proportional to the anode mass flow rate in a particular voltage range. For both mass flow rates illustrated, the current remains constant until the voltage drops to a characteristic value (about $200 \mathrm{~V}$ ) then increases as the voltage continues to drop.

Figure 6 illustrates thrust as a function of time and anode mass flow rates. Thrust depends on acceleration voltage and anode mass flow rate. ${ }^{25,26}$ As the acceleration voltage decays with time, the momentum change for a particular anode mass flow rate exerted on the plasma decreases, generating less thrust. Since the stating voltages at $\mathrm{m}_{\mathrm{a}}=4.57 \mathrm{mg} / \mathrm{s}$ were all the same, the thrust waveforms trace each other very well. However, the voltage dependence of thrust is clarly observed for the wo thrust waveforms at $\mathrm{m}_{\mathrm{a}}=3.29 \mathrm{mg} / \mathrm{s}$, which resemble each other hut are separated.

Figure 7 shows thrust as a function of power and mass flow rates. Thrust increases with increasing flow rate at given power levels, thus acheving higher thrust at the expense of accelarition voltage. In the cases illustrated, the thrust drops at the end of a run to about $70 \%$ of 

its initial value due to the decrease in acceleration voltage. The thrust pulse at $\mathrm{m}_{a}=4.57 \mathrm{mg}$ 's (210 s as shown in Figure 6 ) is about $40 \%$ shorter than that at $\mathrm{m}_{\mathrm{a}}=3.29 \mathrm{mg}$ 's $(350 \mathrm{~s}$, also Figure 6). Thrust decreases linearly with decreasing power.

Figure 8 shows the specific impulse as a function of power and mass flow rates for both anode (indices $a$ ) and total mass flow rates (indices $a c$ ), respectively. The highest specific impulse at a given power level occurs at the lowest anode and total mass flow rates, while a higher specific impulse is obtained in all cases by increasing voltage and decreasing current. The specific impulse considering total mass flow is, on average, $18 \%$ lower for $\mathrm{m}_{\mathrm{a}}=3.29 \mathrm{mg} / \mathrm{s}$ and $12 \%$ lower for $\mathrm{m}_{\mathrm{a}}=4.57 \mathrm{mg} / \mathrm{s}$ anode flow rate with respect to the specific impulse excluding cathode flow rate. At higher anode mass flow rates the cathode flow rate fraction is less dominant, resulting in a smaller deviation of performance values. Overall, the specific impulse covers a range between $1000 \mathrm{~s}$ and $2200 \mathrm{~s}$ for anode mass flow rates from 3.04 to $4.57 \mathrm{mg} / \mathrm{s}$.

Figure 9 illustrates the efficiency as a function of power in the same manner as Figure 8 . The diagram shows that for the indicated propellant mass flow rates, efficiency approaches a value of $\sim 60 \%$ (excluding cathode mass flow) and $\sim 50 \%$ (for total mass flow) with increasing power input. High efficiencies are achieved with greater propellant mass flow rates and power inputs. Similar to Figure 8, the effect of excluding the cathode mass flow rate in the efficiency calculation is significant and is on average $16 \%$ higher for $\mathrm{m}_{\mathrm{a}}=3.29 \mathrm{mg} / \mathrm{s}$ and $10 \%$ higher for $\mathrm{m}_{\mathrm{a}}=4.57 \mathrm{mg} / \mathrm{s}$ anode mass flow.

Figure 10 relates efficiency as a function of specific impulse and mass flow rates excluding cathode mass flow. Similar to the results shown in Figure 9, the efficiency as a function of specific impulse approaches an upper value with increasing specific impulse for any given propellant mass flow rate. The efficiency varies from 35 to $60 \%$ for anode mass flow rates between 3.29 and $4.57 \mathrm{mg} / \mathrm{s}$ in the specific impulse range of 1100 to $2.300 \mathrm{~s}$.

\section{MISSION ANALYSIS}

The mission analysis is performed with respect to datg makeup of the ORACIE: (Ozone

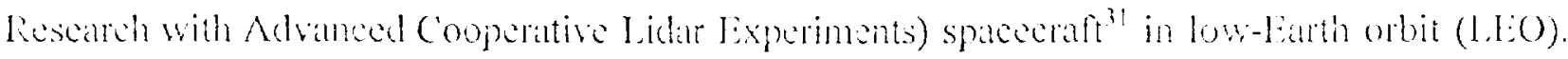


NASA and the Canikdian Space Agency (CS.1) jointly initiated the development of a spaceborne ozons/acrosol measuring and profiling system to determine the global impact (temperature profile in the stratosphere, tropospheric climate, health risks, etc.) of changes in natural ozone layers. ${ }^{32}$ The ORACLE spacecraft is currently in the conceptual stage to study the feasibility, placement and operation requirements of an autonomous, compact DIfferential Absorption Lidar (DIAL) ${ }^{33}$ instrument in space. The spacecraft has an initial mass of $1000 \mathrm{~kg}$ and a projected area of $5 \mathrm{~m}^{2}$, not including solar arrays. The payload of the spacecraft is powered by a $600 \mathrm{~W}$ solar array from which none of the power is allocated to the propulsion system. To investigate the impact of solar arrays on the drag behavior of the spacecraft, two orbits with a two year lifetime are considered for the analysis and will be described in the next section.

\section{Orbit Options}

The mission is to keep the spacecraft in a $300 \mathrm{~km}$, sun synchronous orbit for two years. The operational orbital band is assumed to be between 299 and $301 \mathrm{~km}$. A propulsion system must be in place to produce a representative velocity $(\Delta v)$ to compensate for drag in LEO. The two sun synchronous orbits considered in this analysis are a $6 \mathrm{am} / 6 \mathrm{pm}$ and $12 \mathrm{am} / 12 \mathrm{pm}$ trajectory. The $6 \mathrm{am} / 6 \mathrm{pm}$ sun synchronous orbit is inclined $96.67^{\circ}$ with respect to the equatorial plane and experiences shading only a few months per year. ${ }^{34}$ In this orbit, the $600 \mathrm{~W}$ payload solar array is assumed to fly edge on with respect to the velocity vector, thus causing negligible drag. The plane of the $12 \mathrm{am} / 12 \mathrm{pm}$ sun synchronous orbit also is inclined $96.67^{\circ}$ with respect to the equatorial plane and encounters maximum shading of $36.6 \mathrm{~min}$. every $90.5 \mathrm{~min}$. orbit. Since the solar arrays are always oriented towards the sun and exposed perpendicular to the incoming sun rays, this orbit introduces significant drag. For this analysis it is assumed that a drag area of half the solur array area is present all the time.

To account for drag influence of the upper atmosphere on the orbit, two cases were chosen to repesent an all-time average and a solur maximum atmospheric density. The atmospheric model

used predicts $2.7 \times 10^{-11} \mathrm{~kg} / \mathrm{m}^{3}$ for the average atmospheric density and $5.2 \times 10^{-11} \mathrm{~kg} / \mathrm{m}^{3}$ for the 
maximum atmospheric density. Reference $3 t$ includes a more detailed discussion of atmospheric density models and prediction.

\section{Power Options}

The power options for the electric propulsion systems considered for this analysis are Ga.As solar arrays supplying energy to either recharge a CDL capacitor bank or to power a Hall-ion thruster via a power processing unit (PPU). The GaAs solar array yields $224 \mathrm{~W} / \mathrm{m}^{2}$ and has a mass-to-power ratio of $53 \mathrm{~kg} / \mathrm{kW}$. Depending on the power requirements of both the arraydriven and the direct-drive system, solar arrays are added to the existing $600 \mathrm{~W}$ payload solar array of the spacecraft. The PPU of the array-driven Hall-ion thruster has an efficiency of $92 \%$ and a mass-to-power ratio of $10 \mathrm{~kg} / \mathrm{kW}$. Similarly, the capacitor banks are assumed to have an efficiency of $98 \%$, since the total input/output losses are very small. The necessary switching and network circuitry for the direct-drive concept will achieve a mass-to-power ratio of about 1 $\mathrm{kg} / \mathrm{kW}$. Four CDL capacitor banks based on different performance characteristics were selected for the analysis and configured to provide the necessary Hall-ion operation characteristics.

Table 3 lists performance characteristics of both CDL capacitor units and the resulting capacitor banks as a function of manufacturer. CDL capacitor units made by Panasonic and Maxwell are based on organic electrolytes allowing voltages up to $3 \mathrm{~V}$ per cell, while SPI and Dornier use aqueous electrolytes limiting the voltage to about $1 \mathrm{~V}$ per cell. Thus in the case of SPI and Dornier, a unit consists of many cells wired in series leading to operating voltages of about $25 \mathrm{~V}$ per unit. A bank consists of an appropriate number of capacitor units wired in series to fulfill the voltage requirements of the Hall-ion thruster. The Dornier bank consists of 15 subbanks wied in parallel, while a sub-bank has 16 capacitor units wired in series. This configutation increases the energy stored in the bank by $1500 \%\left(E_{\text {sub-bark }}=13.5 \mathrm{~kJ} \rightarrow \mathrm{E}_{\text {bunk }}\right.$ $=202.5 \mathrm{~kJ})$ and significantly reduces the equivalent series resistance by $93 \%\left(\mathrm{ESR}_{\text {suh-buk }}=3.2 \Omega\right.$ -> $\operatorname{ESR}_{\text {bunk }}=0.213 \Omega$ ). Since the capacitor banks power the Hall-ion thrusters between a voltage of $400 \mathrm{~V}$ and $150 \mathrm{~V}$, about $14 \%$ of the energy remains in the bank and cannot be used by the thruster. For the mission analysis, the Hall-ion thrusters are assumed to operate at only one 
power point which, in the case of the direct-drive system. will represent an average operating power point.

\section{Propulsion Options}

To perform the mission analysis, the direct-drive concept, a conventional continuous drive system, and a state-of-the-art hydrazine monopropellant system ${ }^{35}$ are considered to accomplish the mission profile. Table 4 summarizes thruster characteristics considered in the analysis and provides an overview for quick reference. The direct-drive system consists of a single $1200-\mathrm{W}$ Hall-ion thruster powered directly by a capacitor bank, while the energy to recharge the bank is supplied directly by solar arrays added to the existing payload solar array. As discussed earlier, four CDL capacitor banks based on different performance characteristics are selected and configured to provide the necessary Hall-ion operation characteristics. In the conventional continuous drive system, solar arrays added to the existing payload solar arrays provide power to a $1200-\mathrm{W}$ Hall-ion thruster. The thruster has a specific impulse of $1400 \mathrm{~s}$ and an efficiency of $55 \%$. The engine produces a thrust of $95 \mathrm{mN}$ according to:

$$
T=\frac{2 \cdot \eta_{T} \eta_{p p_{l}} \cdot P}{l_{s p} g_{0}}
$$

with a mass flow of $6.9 \mathrm{mg} / \mathrm{s}$ according to:

$$
\dot{m}=\frac{T}{l_{s p} g_{0}}
$$

in the direct-drive case, and $88 \mathrm{mN}$ with $6.4 \mathrm{mg} / \mathrm{s}$ in the continuous system. Note, that the lower thrust achieved with the continuous system results from the lower PPU efficiency for this configuration (Table 4).

These two Hall-ion configurations (Figure 11) are compared to a state-of-the-art (SOA) hydrazine monopropellant thruster which will provide a baseline for comparison. The baseline system has a specific impulse of $225 \mathrm{~s}$ and the two engines combined will generate $4.45 \mathrm{~N}$ of thrust at a total mass flow rate of $2 \mathrm{~g} / \mathrm{s}$. 


\section{MISSION ANALYSIS RESLLTS}

Drag compensation for the ORACLE spacecraft is the primary mission in this preliminary study evaluating electric and chemical propulsion to fulfill the task. The mission analysis consisted of a simple iterative routine providing mission characteristics for the two orbits discussed above under both solar average and solar maximum atmospheric density conditions. However, the model did not take into consideration daily atmospheric variations which may not be negligible under certain circumstances. It calculated the amount of circular orbit altitude changes under the assumption of constant drag force versus the thrusting force over a circular orbit. Further, it is assumed that the thrusters in all propulsion options are pointed in the tangential direction at all times during firing. In some cases, when employing CDL capacitor banks to provide energy to the thruster, the thruster burn time was increased by considering several banks subsequentially discharged. This concept reduced the number of thruster firing cycles which was limited to 30,000 , and increased thruster lifetime. ${ }^{37}$

The analysis routine had been previously used to evaluate preliminary mission characteristics of both a low power electrothermal thruster ${ }^{35}$ and a Hall-ion thruster. ${ }^{36}$ The input data consisted of the spacecraft specifications, orbit parameters, power system characteristics (Table 3), and propulsion system characteristics (Table 4). The output data and their name definitions are described briefly in the following section.

The target characteristics of the mission analysis are available net mass, two-year system wet mass, and electric propulsion power requirements as the main output parameters of the routine. Specifically, it is desirable to increase available net mass, and to reduce both system wet mass and electric propulsion power requirements. The wet mass is defined as the mass of all components attributed to the propulsion system for a particular spacecraft lifetime. Among others, this includes thruster mass, propellant mass, power plant mass (solar array, cap bank, PPU, ete.), and structure mass. The net mass is usable spacecraft mass (initial mass minus wet propulsion mass). Other output parameters are burn time per charge, duty cycle, capacitor charge time, power for charging capacitors, and solar array mass for electric propulsion. The burn tine per capacitor charge cycle is defined as 


$$
t_{h}=\frac{n \cdot E_{m c}}{P_{l}}
$$

while the useable capacitor energy is calculated with

$$
E_{\text {u.e }}=0.86 \cdot E_{\text {strots }}=0.86 \cdot \frac{1}{2} \mathrm{Cr}^{2}
$$

Due to the CDL capacitor bank discharge from $400 \mathrm{~V}$ to $150 \mathrm{~V}$, about $14 \%$ of the stored energy remains in the capacitor bank and is not available for propulsion, thus the 0.86 factor.

The duty cycle is also an important parameter, indicating how long the thruster is burning per cycle as compared to the total cycle time. The duty cycle $\lambda$ is expressed as the ratio of time to raise the spacecraft from the bottom to the top of the orbit band (i.e. from $299 \mathrm{~km}$ to $301 \mathrm{~km}$ ) and the sum of time to raise the spacecraft to the top of the orbit band and then to drag down to the bottom of the orbit band. With the definitions above, the time to charge the capacitor bank is calculated as

$$
t_{\text {charge }}=\frac{t_{b}}{\lambda}
$$

The power needed to charge the CDL capacitor banks and enable direct-drive electric propulsion is now determined as

$$
P_{E P}=\frac{n \cdot E_{\text {use }}}{t_{\text {charge }} \cdot 0.95}
$$

The charging circuitry is assumed to be $95 \%$ efficient. The mass of the solar arrays to provide the power needed for electric propulsion is calculated with the mass-to-power ratio for GaAs solar arrays of $53 \mathrm{~kg} / \mathrm{kW}$.

\section{Case I: $6 \mathrm{am} / 6 \mathrm{pm}$-Orbit with Solar Average Atmospheric Density}

Case I considers a $6 a \mathrm{~m} / 6 \mathrm{pm}$ sun synchronous orbit with an average altitude of $300 \mathrm{~km}$ and a solar average atmospheric density of $2.7 \times 10^{-11} \mathrm{~kg} / \mathrm{m}^{3}$. This orbit encounters shading for approximately four months per year; however, this analysis assumed no shading all year around to illustrate the impact of maximum shading as experienced in the $12 \mathrm{am} / 12 \mathrm{pm}$ sun synchronous orbit on the mission analysis. 
Figure 12 illustrates the results of available net mass and two year system wet mass as a function of propulsion option, while Table 5 summarizes the mission characteristics obtained for the solar average atmospheric density assumption. Both the figure and the table allow for easy comparison with the state-of-the-art (SOA) hydrazine monopropellant propulsion option, which was chosen as a baseline in this study.

The available net mass increase for CDL capacitor direct-driven (CDD) options ranges from 6 to $18 \%$, while the $1200 \mathrm{~W}$ solar-array driven option (1200W/SA) achieves $14 \%$. Similarly, CDD options yield a decrease in two-year wet mass of 18 to $58 \%$ and the $1200 \mathrm{~W} / \mathrm{SA}$ option achieves a $46 \%$ reduction.

To increase the burn time, three and six basic CDL capacitor banks are considered for the Dornier and SPI option, respectively. Due to the relative short burn times of the CDD options, the number of thruster cycles is very high. This will consequently control the lifetime of the cathode. ${ }^{37}$

All CDD options are characterized by a low duty cycle of $9 \%$ and low solar array power of $111 \mathrm{~W}$ which has to be considered in addition to the payload solar array of $600 \mathrm{~W}$. This is approximately $1 / 10$ of the $1200 \mathrm{~W} / \mathrm{SA}$ power (i.e. mass). The low power requirements and consequently the reduction in solar array size in the CDD options will have an impact on complexity of satellite design and packaging. In addition, solar array size reduction and low capacitor prices are expected to significantly reduce system cost.

\section{Case II: 6am/6pm-Orbit with Solar Maximum Atmospheric Density}

Similar to orbit conditions of Case I, Case II considers a solar maximum atmospheric density of $5.2 \times 10^{-11} \mathrm{~kg} / \mathrm{m}^{3}$. Figure 13 illustrates the results obtained for net and wet mass as a function of propulsion option, while Table 6 summarizes the mission characteristics for the solar maximum atmospheric density condition. The results in both the figure and the table are compared to the SOA propulsion option.

For this case, the increase of available net mass is significant for all electric propulsion options when compared to the SOA system. The available net mass of the SOA propulsion 
system drops by almost $25 \%$ under the higher solar atmospheric density condition. while the net mass for the electric propulsion options only decreased on the average of $5 \%$. The combined result is a net mass increase of 28 to $42 \%$ when compared to the baseline. The SOA wet mass increases by $75 \%$ leading to a reduction of 41 to $63 \%$ with electric propulsion options.

Due to the higher solar atmospheric density, a second CDL capacitor bank had to be considered in the Panasonic CDD option to limit the number of cycles to below 30,000 . Similar to the previous case, Maxwell has the lowest cycle number of all CDD options, while SPI and Dornier exceeded Panasonic and are now in the same range. Although the solar-array driven thruster has cycle numbers two orders of magnitude smaller, the total burn time is $20 \%$ higher when compared with CDD options.

The duty cycle of the CDD systems is $18 \%$ for all electric propulsion options versus $19 \%$ for $1200 \mathrm{~W} / \mathrm{SA}$. Due to the higher mission requirements for Case II, a shorter charge time is required and can be accommodated by increasing the solar array power dedicated to capacitor charging. The required power doubles to $222 \mathrm{~W}$ when compared to Case I.

\section{Case III: 12am/12pm-Orbit with Solar Average Atmospheric Density}

Case III considers a $12 \mathrm{am} / 12 \mathrm{pm}$ sun synchronous orbit with an average altitude of $300 \mathrm{~km}$ and a solar average atmospheric density of $2.7 \times 10^{-11} \mathrm{~kg} / \mathrm{m}^{3}$. This orbit encounters maximum shading for $36.6 \mathrm{~min}$. every $90.5 \mathrm{~min}$. orbit. Figure 14 illustrates the results of available net mass and two year system wet mass as a function of propulsion option, while Table 7 summarizes the mission characteristics obtained for the solar average atmospheric density assumption.

The shading in this orbit impacts the charge time and requires a larger, dedicated solar array for the CDD propulsion options. However, the Panasonic, SPI, and Dornier capacitor banks can be charged during the sun periods and fired during shading. This causes a duty cycle increase of $3 \%$ when compared with Case I, but still remains the lowest of all electric propulsion options (17\% for $1200 \mathrm{~W} / \mathrm{SA})$. Due to the increased drag caused by the larger solar array (i.e. duty cycle), the thruster burn times are high in the $1200 \mathrm{~W} / \mathrm{SA}$ case. In addition, this raises the total mission $\Delta v$, since this propulsion option has no means of storing energy and cannot fire during 
shadling periods. The power to charge the capacitor banks results in $252 \mathrm{~W}$ yielding a solar array mass of $13 \mathrm{~kg}$. The number of thruster cycles is extremely high for all CDD (between 23,000 and 28.500) options except the Maxwell option $(8,000)$, which is still one order of magnitude higher than the solar-array driven option (553).

The available net mass increase ranges between $10 \%$ for SPI and $22 \%$ for Dornier and is on average $4 \%$ higher than the results obtained for the non-shaded cases under the same solar atmospheric conditions. The results for the two year system wet mass range from 25 to $56 \%$. The two year wet mass decrease for Panasonic drops $14 \%$ points when compared with the results of Case I, since an additional capacitor bank was added to increase the thruster burn time.

\section{Case IV: 12am/12pm-Orbit with Solar Maximum Atmospheric Density}

Similar to orbit conditions of Case III, Case IV considers a solar maximum atmospheric density of $5.2 \times 10^{-11} \mathrm{~kg} / \mathrm{m}^{3}$. Figure 15 illustrates the results obtained for net and wet mass as a function of propulsion option, while Table 8 summarizes the mission characteristics for the solar maximum atmospheric density condition. The results in both the figure and the table are compared to the SOA propulsion option.

Similar to Case II, a significant increase in both net and wet mass can be observed. The available net mass of the SOA propulsion system drops down to $54 \%$ of the total spacecraft mass. Maxwell and Dornier are on the top with $47 \%$ net mass increase and $55 \%$ wet mass decrease. The lower boundary is indicated by $21 \%$ and $25 \%$, respectively for the SPI case.

Due to the higher atmospheric density, CDL capacitor banks are added to increase thruster burn time, limit number of burn cycles, and increase energy storage capability. An additional consequence of the higher density is the duty cycle, which is $24 \%$ for CDD and $33 \%$ for the solar-array driven propulsion system. The increased duty cycle governs the capacitor charge time, and consequently the power needed to charge the capacitors. For Case IV, Panasonic neds $519 \mathrm{~W}$ of solar array power, while SPI, Maxwell and Domier require $409 \mathrm{~W}$. This is still 57 to $66 \%$ less solar array power and mass than for the 1200 W/SA electric propulsion option. The total thruster burn time is about $21 \%$ less for SPI, Maxwell, and Dornier when compared with 
$1200 \mathrm{~W} / \mathrm{SA}$. Similarly to all other cases. the number of thruster cycles is extremety high for CDD options, except for Maxwell.

In summary, based on the model results of all cases considered:

- all electric propulsion options are superior to the baseline chemical propulsion in terms of net mass; and

- improvements using electric propulsion options are significant in the cases of higher solar atmospheric density; and

- electric propulsion option with solar array/PPU configuration is characterized by high power needs in providing the necessary energy for electric propulsion; and

- electric propulsion with CDL capacitor bank options meets all three target characteristics in increasing net mass and reducing both two-year system wet mass and electric propulsion power needs.

\section{CONCLUSION}

The direct-drive, CDL capacitor-based concept in electric propulsion promises to be a highlyefficient, viable alternative for satellite operations in specific near-Earth missions. Implementing the direct-drive system in the power train of existing and future satellites will have a major impact on the following:

- power train and network design (simplification)

- propellant mass reduction

- energy storage mass reduction

- life time extension of energy storage

- propulsion subsystem mass reduction due to elimination of power processing and conditioning units

- life extension of satellite and mission

- power requirement reduction

- satellite layout, design, and telemetry

- application range 
- cost efficiency and life-cycle costs

- satellite and mission management.

The CDL capacitor technology used in this research demonstrated many advantages over conventional energy storage technology (e.g. batteries) such as superior volume-to-mass ratio, higher charge-discharge cycle ability, and power densities. The design and integration of a CDL capacitor-based power supply into the power train of a Russian TAL/D-55 was successful, and the feasibility of the direct-drive concept was clearly shown through the experiments conducted at NASA Lewis. The performance characteristics of the CDL direct-driven TAL experiments (e.g. start-up sequences, instabilities, and discharge voltage and current influences) are similar and competitive to the steady-state operation previously investigated.

The preliminary mission analysis completed in this research indicated that although the CDL direct-drive option was competitive with other electric propulsion systems in the areas of increased available net mass and reduced lifetime wet mass, it proved superior in the reduction of electric propulsion power requirements. The reduction in required power could lead to smaller, simpler, and less-expensive satellite solar arrays and power conditioning systems.

\section{ACKNOWLEDGMENTS}

The authors wish to thank the team under the supervision of Dr. Francis M. Curran in the Space Propulsion Technology Division (SPTD) at NASA Lewis Research Center, Cleveland, $\mathrm{OH}$, for their support and assistance which led to the successful completion of this research. Further, the authors would like to acknowledge Steve R. Oleson at NASA Lewis RC for providing background information and performing the mission analysis and Steve Best at Space Power Institute, Auburn University, AL, for his assistance and support in designing the power

supply for charging/discharging the CDL capacitor bank. The research was funded by Space Power Institute and the Center for Commercial Development of Space Power (CCDS) at Auburn University, AL.

\section{REFERENCES}


[1] Casani, E.K., Wilson, B.W., The New Millennium Program: Technologr Development for the 21st Century', AIAA 34th Aerospace Sciences Meeting and Exhibit. AIAA 96-0696, Reno, NV, January 1996.

[2] Rose, M.F., Hrbud, I., Merryman, S.A., 'Application of Chemical Double Layer Capacitor Technology to Pulsed Electric Thrusters', 30th AIAA Joint Propulsion Conference, AIAA 94-3304, Indianapolis, IN, June 1994.

[3] Hamley, J.A., 'Direct Drive Options for Electric Propulsion Systems', NASA TM 106576, 1995.

[4] von Helmholtz, H.L.F., 'Studien ueber elektrische Grenzschichten', Annalen der Physik und Chemie, 7, pp. 337-82, 1879.

[5] Rose, M.F., 'Performance Characteristics of Large Surface Area Chemical Double Layer Capacitors', Proceedings of the 33rd International Power Source Symposium, Journal of Electrochemical Society, Penningham, NJ, 1988.

[6] Rose, M.F., Lai, J., Levy, S., 'High Energy Density Double-Layer Capacitors for Energy Storage Applications', IEEE Aerospace and Electronics Systems Magazine, Vol. 7, No. 4, 1992, pp. 14-19.

[7] Kurzweil, P., Dietrich, G., 'Double Layer Capacitors for Energy Storage Devices in Space Applications', Proceedings of the 2nd International Seminar on Double Layer Capacitors and Similar Energy Storage Devices, Florida Educational Seminars, Inc., Deerfield Beach, FL, 1992.

[8] Yoshida, A., Nishino, A., Ohara, K., 'Electric Double-Layer Capacitors for High Rate Charge-Discharge Uses', Proceedings of the 2nd International Seminar on Double Layer Capacitors and Similar Energy Storage Devices, Florida Educational Seminars, Inc., Deerfield Beach, FL, 1992.

[9] Piszczor, M.F., O'Neill, M.J., Fraas, L.M., 'Design and Development of a Line-Focus Refiactive Concentrator Array for Space', Procedings of the 29th Intersociety Energy Conversion Fngineering Conference, pp. 282-285. 
[10] Cann. G.L., Marlote, G.L., 'Hall Current Plasma Accelerator'. AlAA Journal. Vol. 2. No. 7 , July 1964.

[11] Jones, G.S., Dotson, J., Wilson. T., Electrostatic Acceleration of Neutral Plasmas Momentum Transfer through Magnetic Field', Proceedings of the Third Symposium on Advanced Propulsion Concepts (Gordon \& Breach Science Publisher, Inc., New York, 1963), pp. 153-175.

[12] Zharinov, A.V., Popov, Yu.S., 'Acceleration of Plasma by a Closed Hall Current', Soviet Physics-Technical Physics, Vol. 12, Aug. 1967, pp. 208-211.

[13] Brown, C.O., Pinsley, E.A., 'Further Experimental Investigation of a Cesium Hall-Current Accelerator', AIAA Journal, Vol. 3, No. 5, May 1965.

[14] Chubb, D.L., Seikel, G.R., 'Basic Studies of a Low-Density Hall Current Ion Accelerator', NASA Technical Note D-3250, Feb. 1960.

[15] Brophy, J.R., Barnett, J.W., Sankovic, J.M., Bernhart, D.A., 'Performance of Stationary Plasma Thruster: SPT-100', AIAA 28th Joint Propulsion Conference, AIAA 92-3155, Nashville, TN, July 1992.

[16] Sankovic, J.M., Hamley, J.A., Haag, T.W., 'Performance Evaluation of the Russian SPT-100 Thruster at NASA LeRC', NASA TM 106401.

[17] Hamley, J.A., Hill, G.M., Sankovic, J.M., 'Power Electronics Development for the SPT-100 Thruster', NASA TM 106488.

[18] Caveny, L.H., Curran, F.M., Brophy, J.R., 'Russian Electric Space Propulsion Evaluated for Use on American Satellites', Paper RGC-EP-93-D2-4, 2nd Russian-German Conference on Electric Propulsion Engines and their Application, Moscow, Russia, July 1993.

[19] Garner, C.E., Brophy, J.R., Polk, J.E., Pless, L.C., 'Performance Evaluation and Life Testing of the SPT-100', 23rd International Electric Propulsion Conference, IEPC 93-091, Seattle, WA, Sept. 1993.

[20] Gamer, C.E., Semenkin, S., Tverdokhlelov, S., Marrese, C., Experimental Evaluation of a Russian Anode Layer Thiuster', 3rd Russian-German Conference on Electric Propulsion Engines and their Application, Stuttgart, Germany, July 1994. 
121/Garner, C.E.. Brophy, J.R., Polk. J.E., Pless, L.C., Cyclic Endarance Test of a SPT-101) Stationary Plasma Thraster', 3rd Russian-German Conference on Electric Propulsion Engines and their Application, Stuttgart, Germany, July 1994.

[22] Semenkin, A.V., 'Investigation of Erosion in Anode Layer Thruster and Elaboration High Life Design Scheme', 23rd International Electric Propulsion Conference, IEPC 93-231, Seattle, WA, Sept. 1993.

[23] Lentz, C.A., Martinez-Sanchez, M., 'Transient One Dimensional Nimerical Simulation of Hall Thrusters', AIAA 29th Joint Propulsion Conference, AIAA 93-2491, Monterey, CA, June 1993.

[24] Komurasaki, K., Arakawa, Y., 'Two-Dimensional Numerical Model of Plasma Flow in a Hall Thruster', 23rd International Electric Propulsion Conference, IEPC 93-230, Seattle, WA, Sept. 1993.

[25] Hrbud, I., 'Evaluation of Performance and Characteristics of Long Pulse Hall-Ion Thrusters Utilizing a Power Source Based on CDL Capacitor Technology', Dissertation, Auburn University, AL, 1997.

[26] Sankovic, J.M., Haag, T.W., 'Operation Characteristics of the Russian D-55 Thruster with Anode Layer', NASA TM 106610, 1994.

[27] Patterson, M.J., et. al. 'Plasma Contactor Development for Space Station', NASA TM106425.

[28] Hrbud, I., 'Direct-Drive Concept Based on CDL Capacitor Technology Powering a Thruster with Anode Layer', 35th AIAA Aerospace Science Meeting, AIAA 97-1007, Reno, NV, Jan. 1997.

[29] Patterson, M.J., Haag, T.W., Rawlin, V.K., Kussmaul, M.T., 'NASA $30 \mathrm{~cm}$ Ion Thrutster Development Status', NASA TM 106842, 1994.

[30] Hamley, J.A., Patterson, M.J., 'Integration Testing of the Space Station Plasma Contactor' Power Electronics Unit', 30th AIAA Joint Propulsion Conference, AIAA 94-3307, June 1994, Indianapolis, IN. 
[31] Campbell, R.E.. Browell, E.V., Ismail. S.. Dudelzak, A.E.. Carswell. A.l.. Ulitsky. A.. 'Feasibility Sudy for a Spaceborne Ozone'Aerosol Lidar System', N/A.

[32] Browell, E.V., et al., 'Ozone and Aerosol Distribution and Air Mass Characteristics Over the South Atlantic Basin During the Burning Season', Journal of Geophysical Research, 100, pp. 1431-1451, 1995.

[33] Browell, E.V., et al., 'NASA Multipurpose Airborne DIAL System and Measurements of Ozone and Aerosol Profiles', Journal of Applied Optics, 22, pp. 522-534, 1983.

[34] Larson, W.J., Wertz, J.R., 'Space Mission Analysis and Design', Microcosom, Inc. Torrance, CA, 1992.

[35] Oleson, S., Sankovic, J.M., 'Benefits of Low Power Electrothermal Propulsion', NASA TM$107404,1996$.

[36] Manzella, D., Oleson, S., Sankovic, J., Haag, T., Semenkin, A., Kim, V., 'Evaluation of Low Power Hall Thruster Propulsion', NASA TM-107326, 1996.

[37] Zakany, J.S., Pinero, L.R., 'Space Station Cathode Ignitions Test Status at 25,000 Cycles', Proceedings of the 25th International Electric Propulsion Conference to be published in Aug. 1997. 


\section{Table of Figures}

Figure 1 - TAL and CDL Capacitor Power Source Direct-Drive Configuration .......................... 2

Figure 2 - CDL Capacitor Structure and Microscopic Chemical Double Lay'er ............................. 3

Figure 3 - Charging/Discharging Power Supply and CDL Capacitor Bank ................................

Figure 4 - Voltage as a Function of Time and Anode Mass Flow Rate .........................................

Figure 5 - Current as a Function of Time and Anode Mass Flow Rate......................................... 6

Figure 6 - Thrust as a Function of Time ……....................................................................... 7

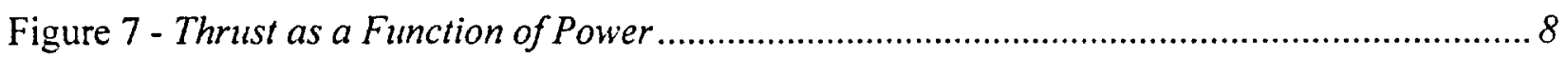

Figure 8 - Specific Impulse as a Function of Power ............................................................... 9

Figure 9 - Efficiency as a Function of Power.......................................................................... 10

Figure 10 - Efficiency as a Function of Specific Impulse .......................................................... 11

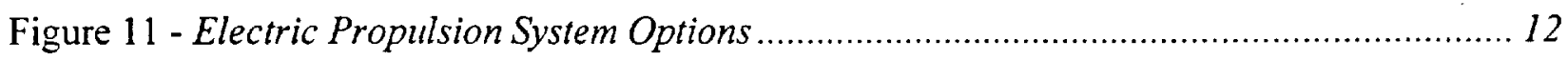

Figure 12 - Mass as a Function of Propulsion System for Case 1............................................. 13

Figure 13 - Mass as a Function of Propulsion System for Case II ............................................ 14

Figure 14 - Mass as a Function of Propulsion System for Case III.......................................... 15

Figure 15 - Mass as a Function of Propulsion System for Case IV ........................................ 16 


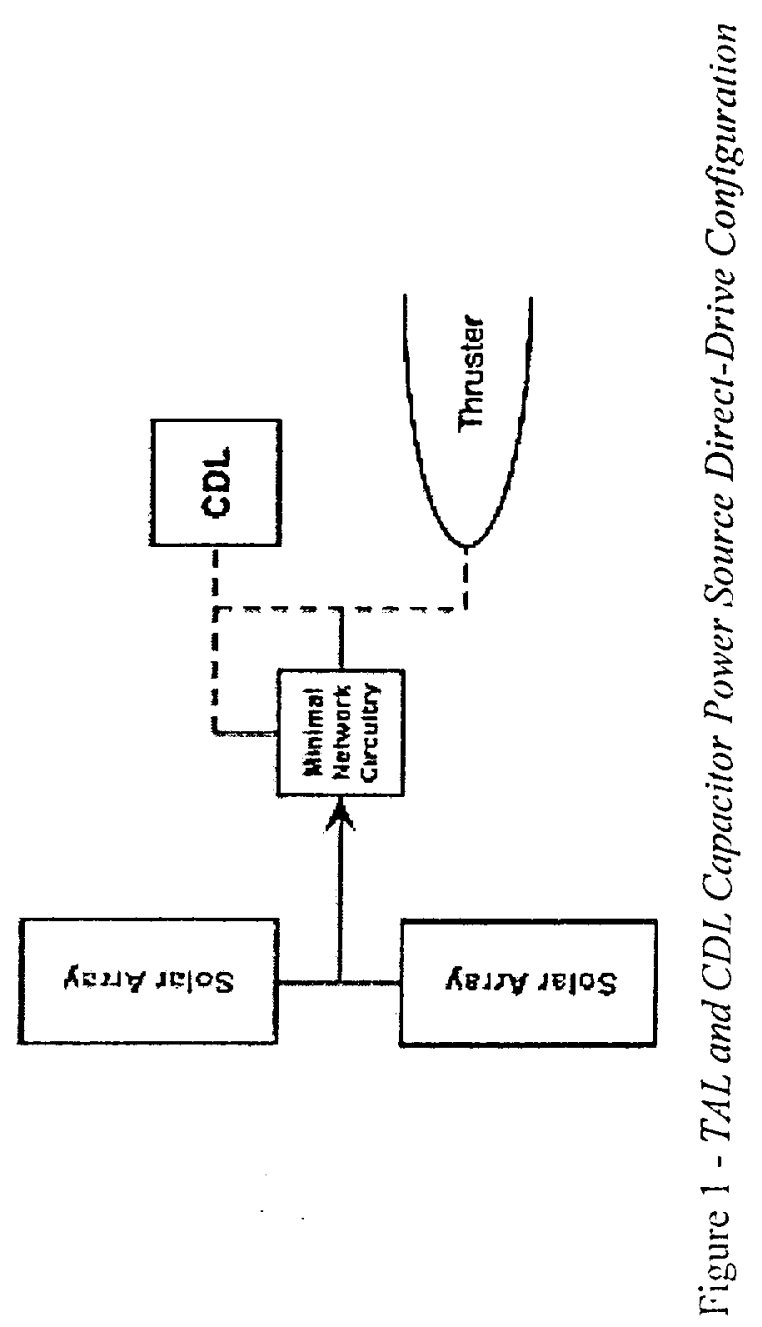




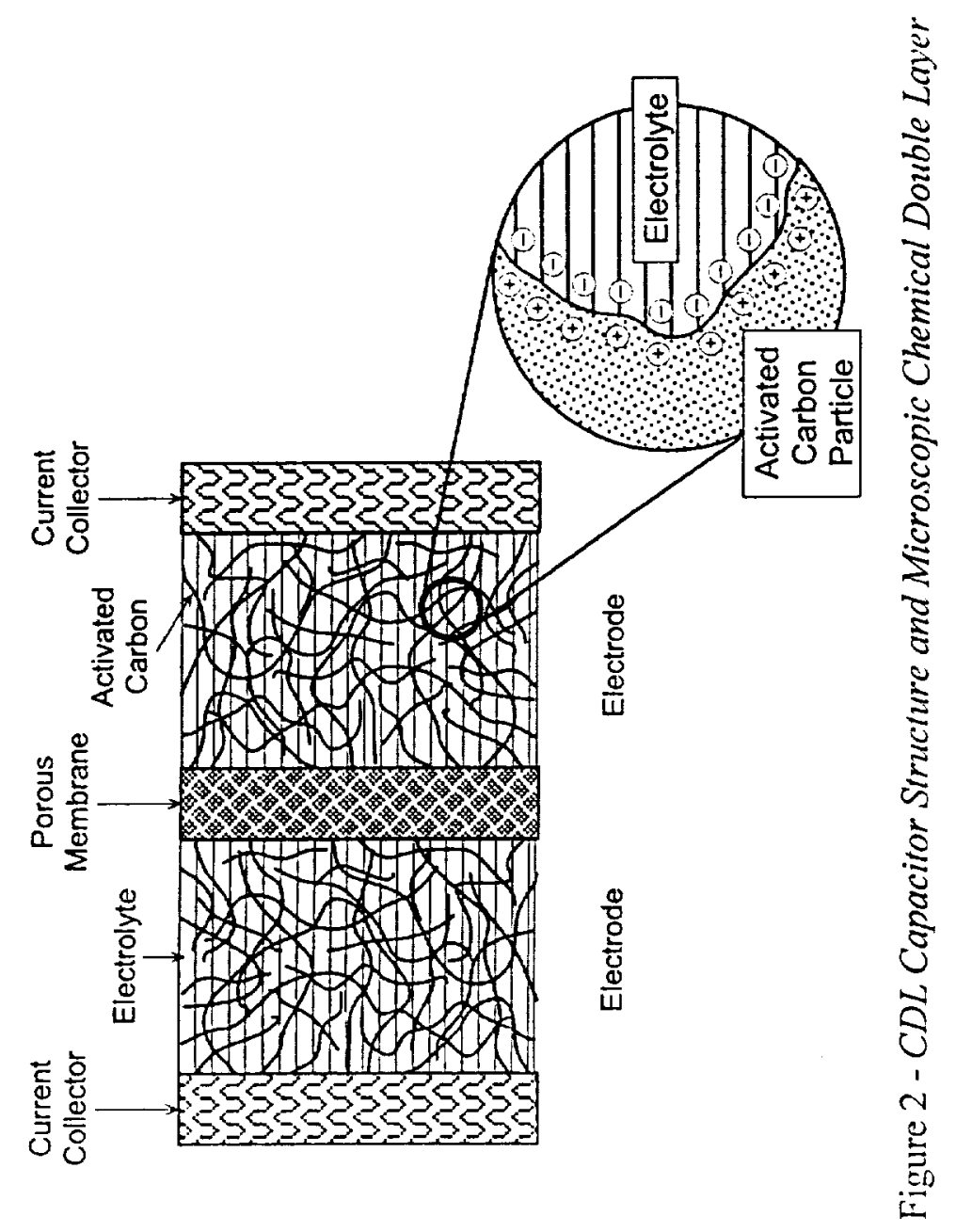

m 


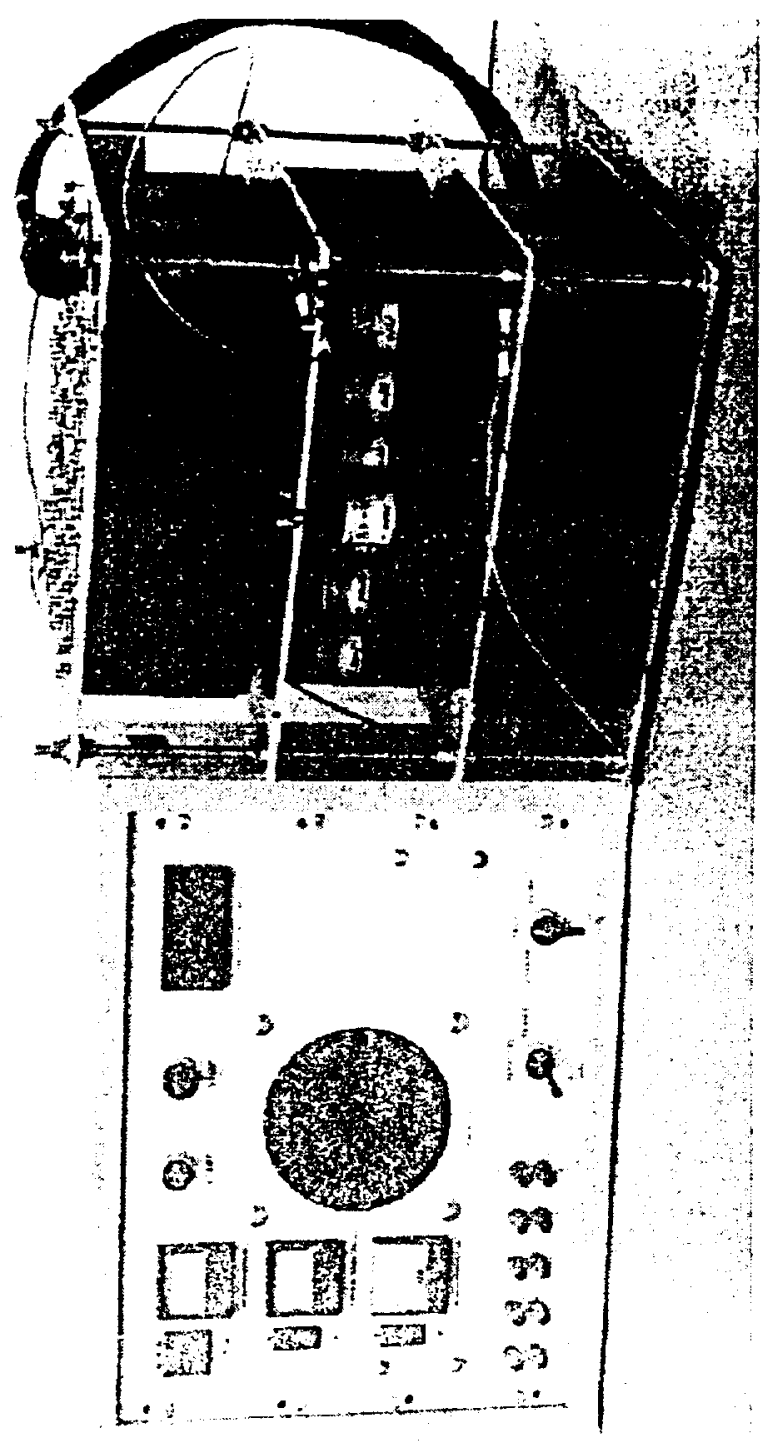

है

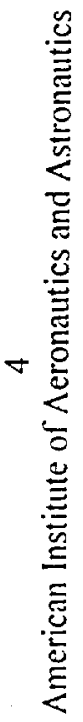




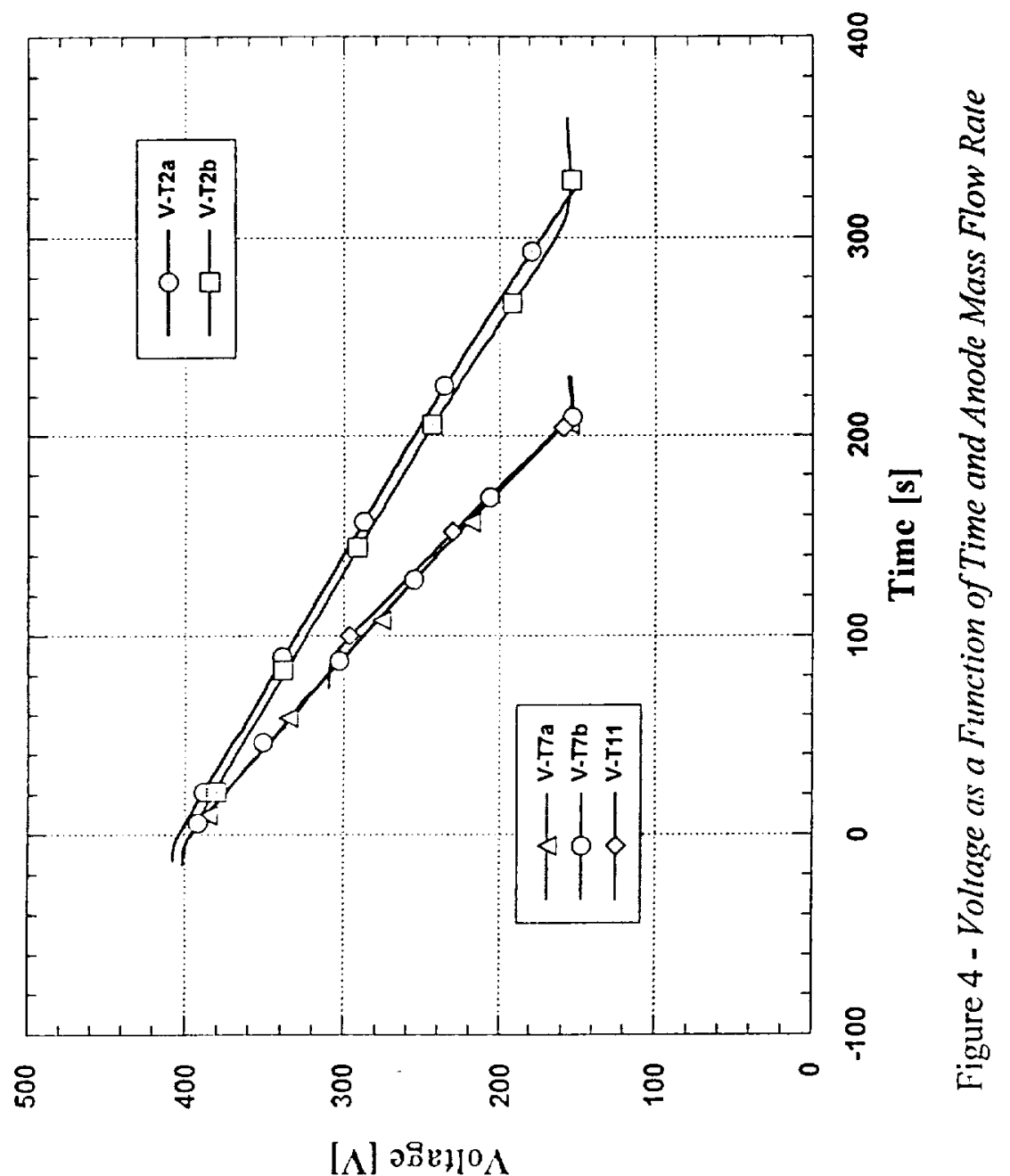




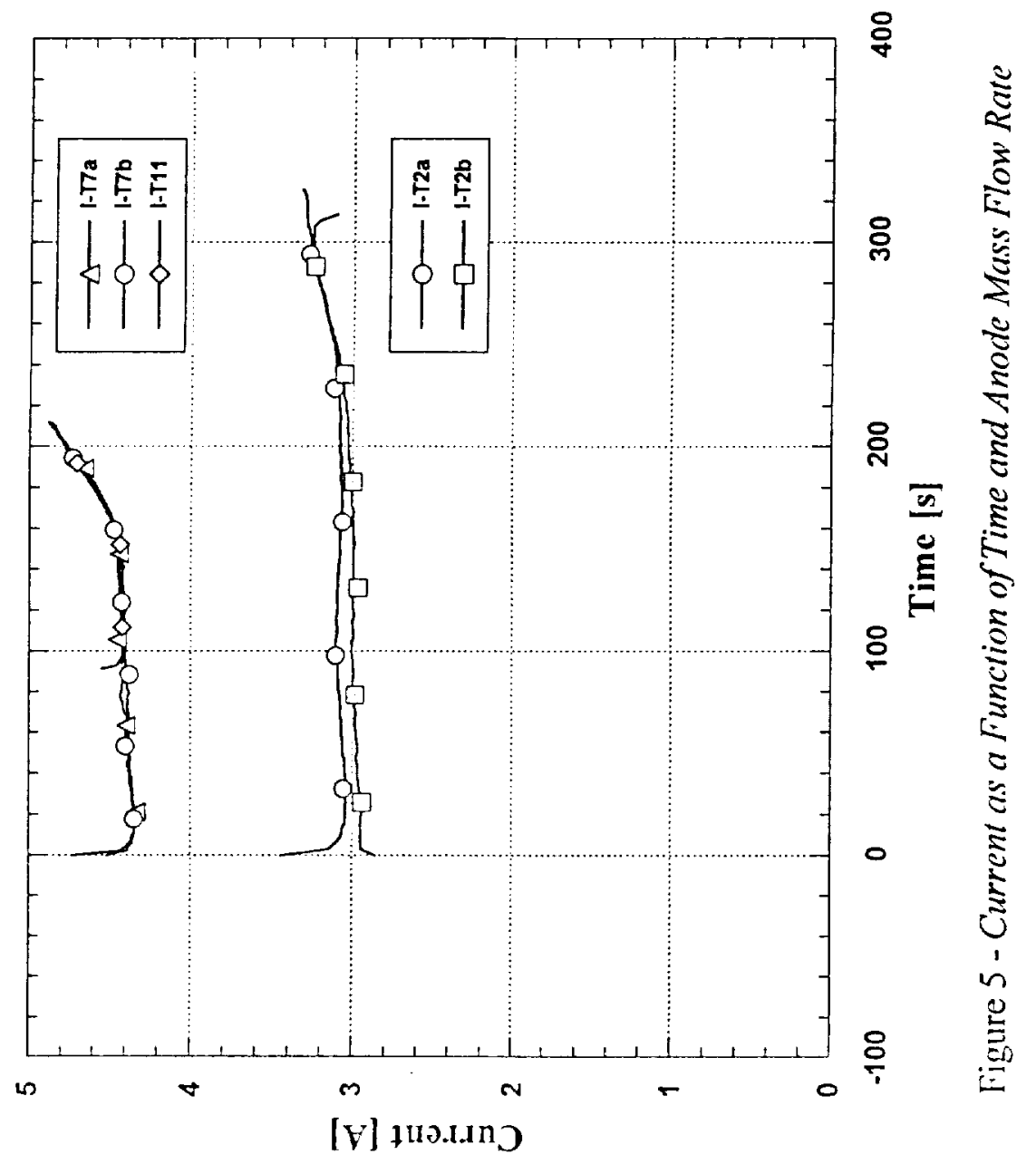




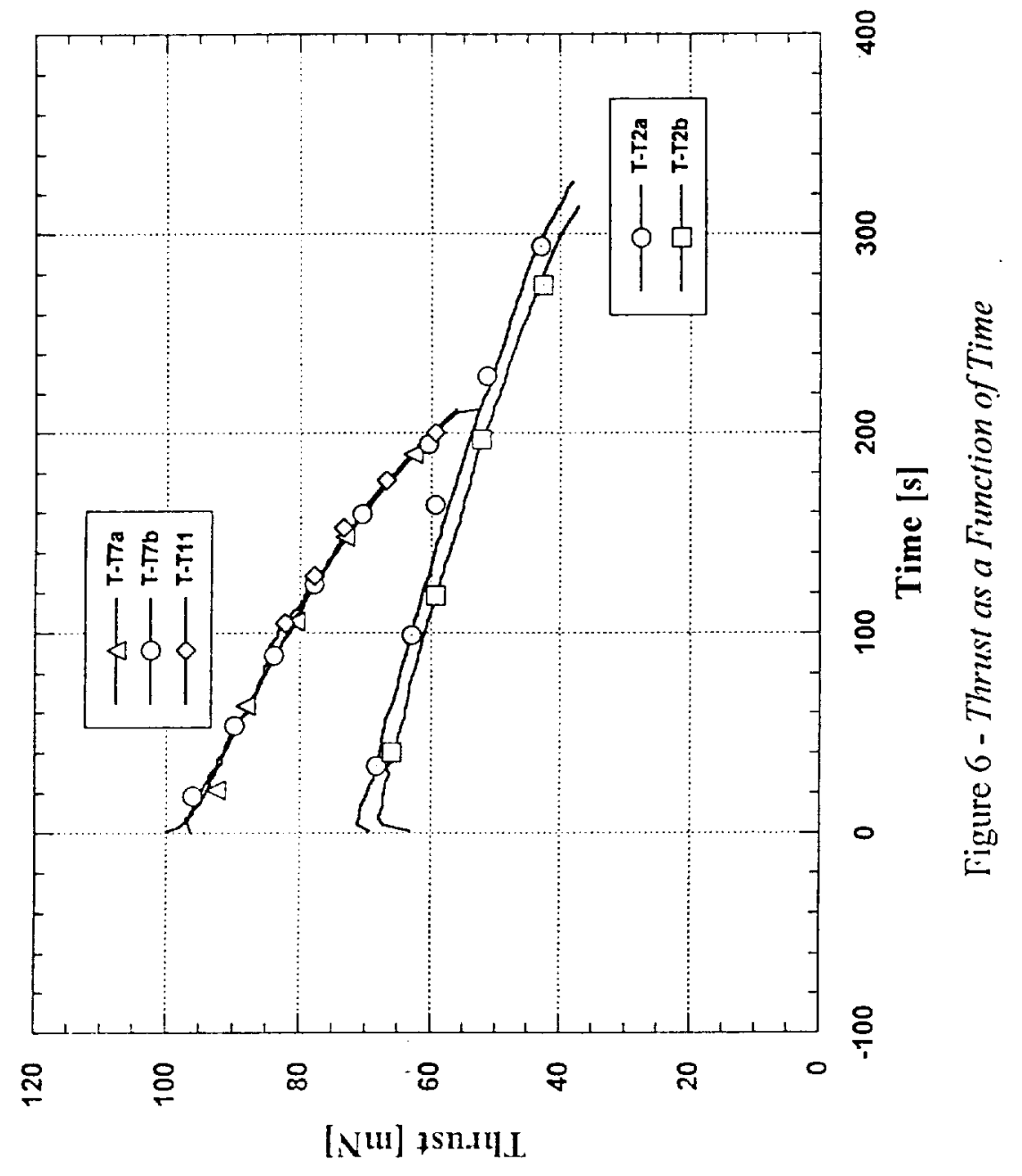

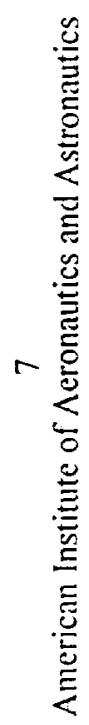




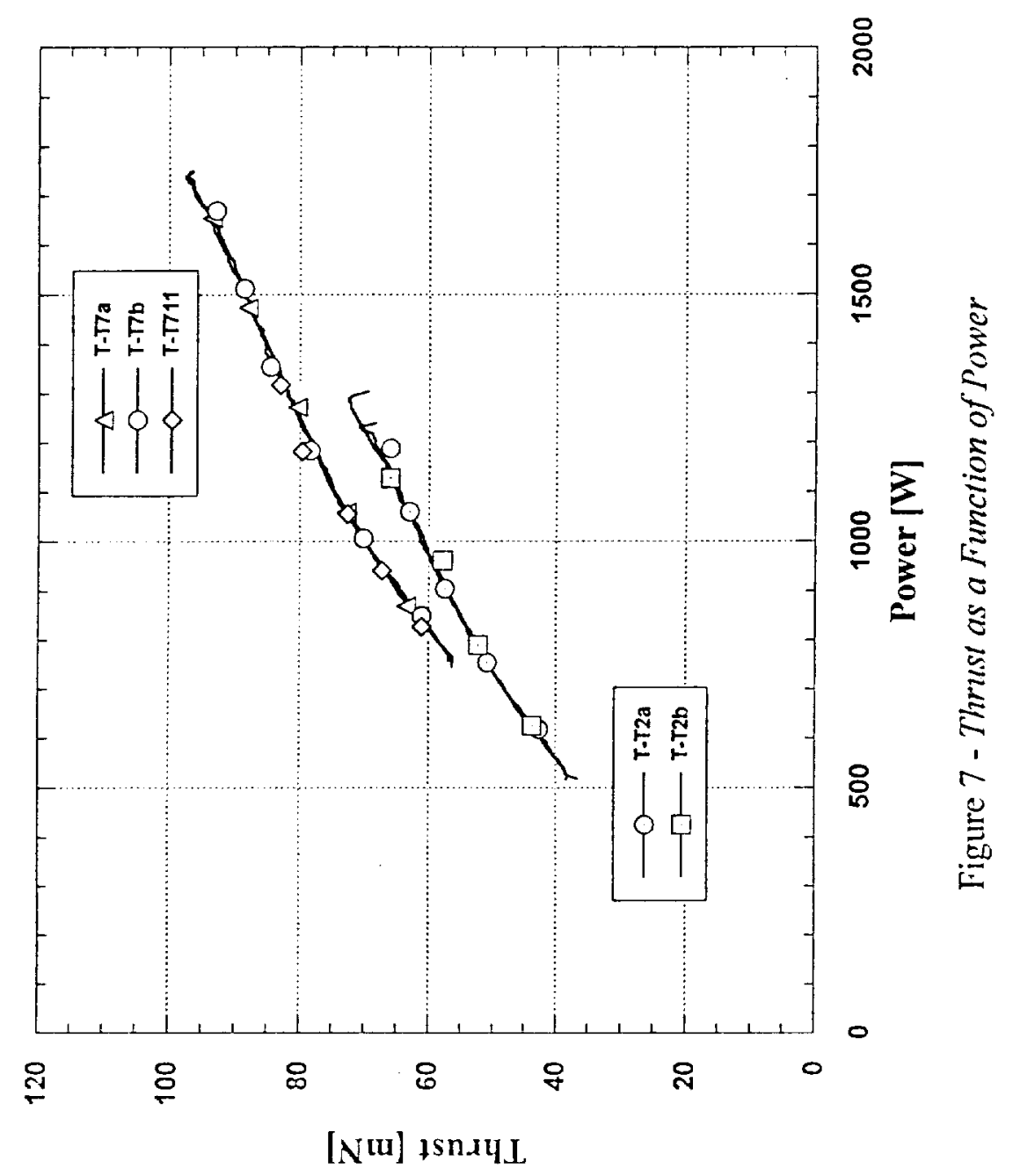

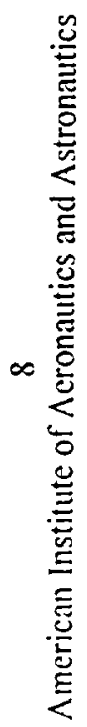



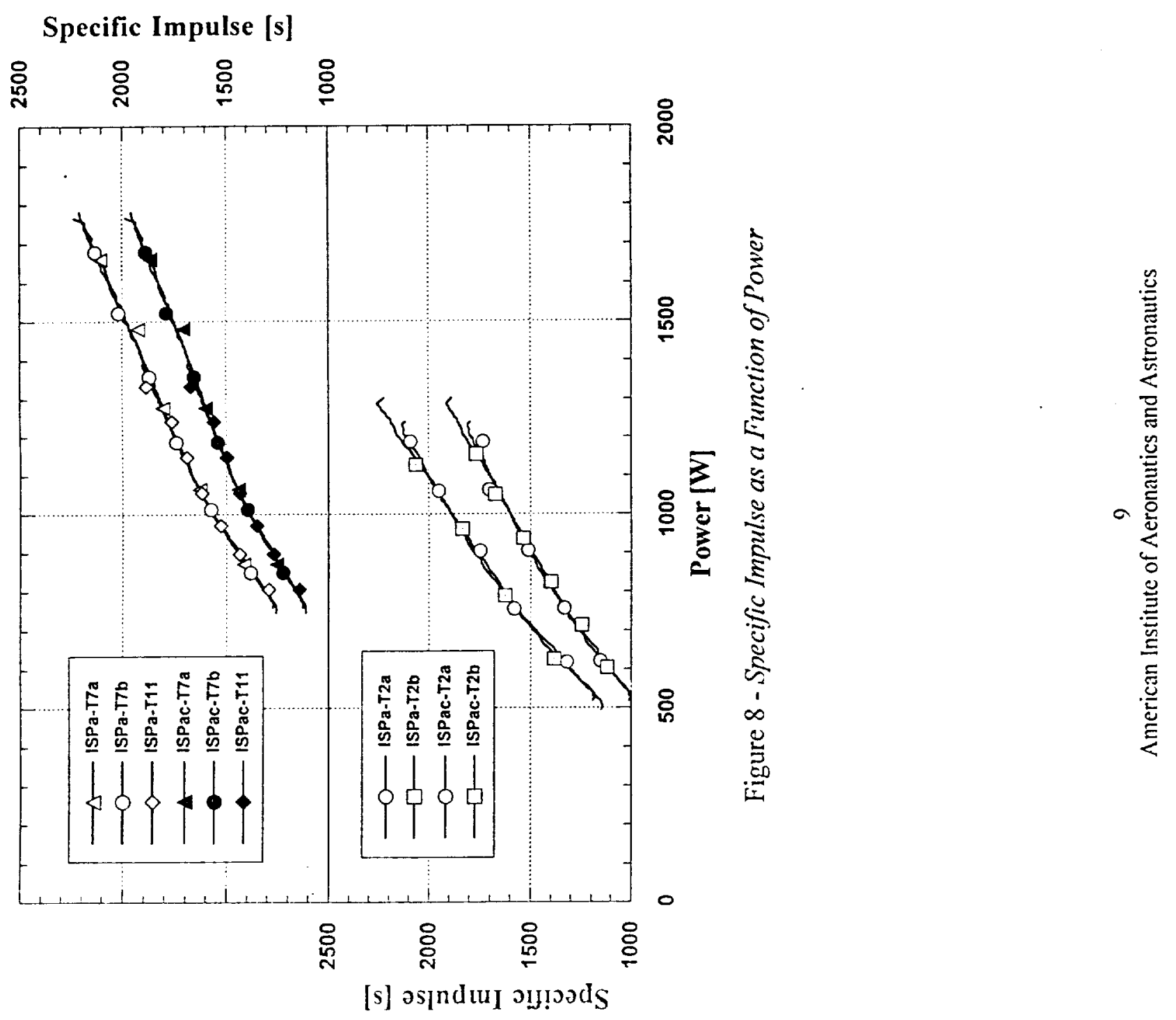


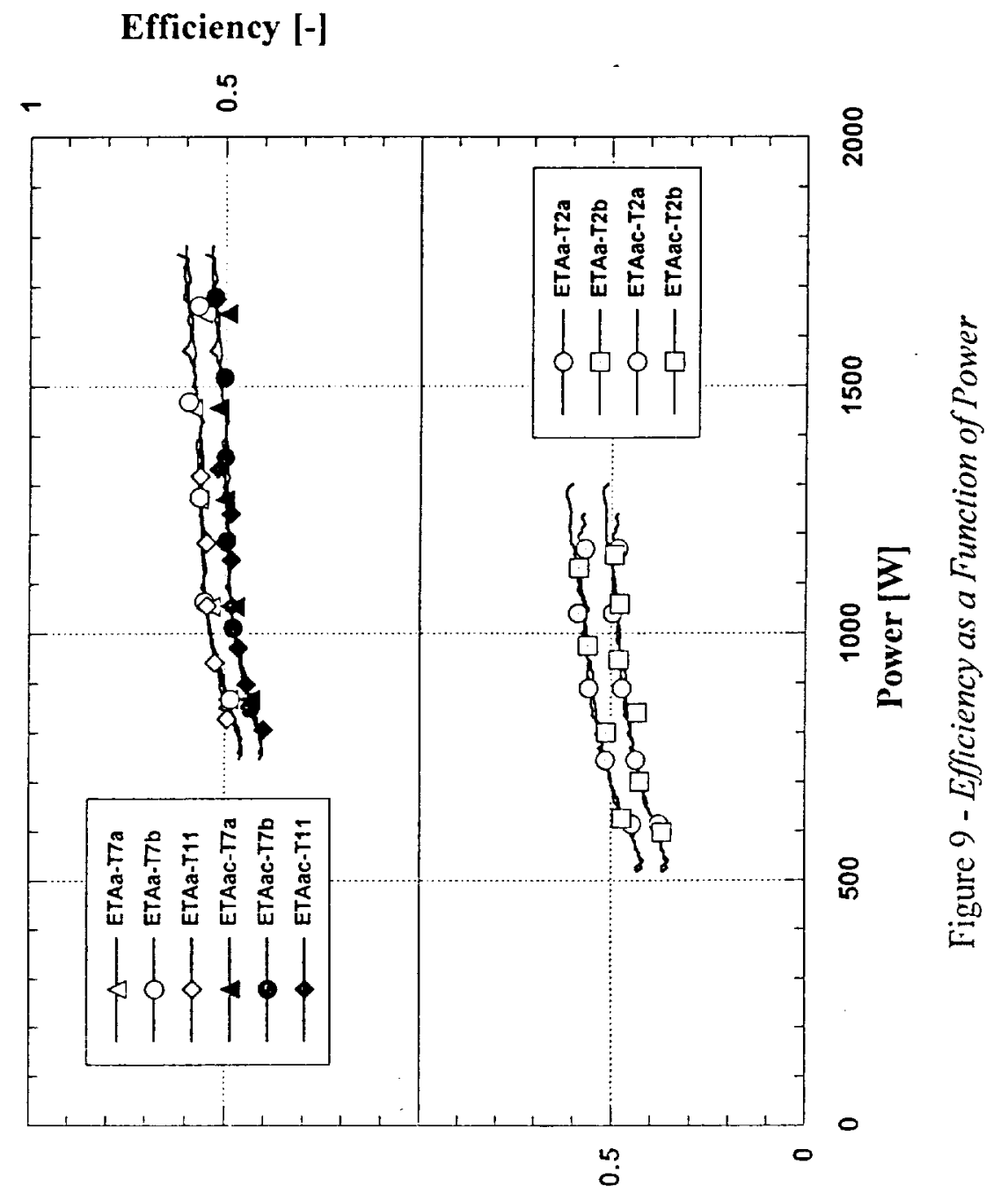

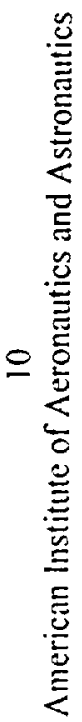

[-] Кวนว!วกม 


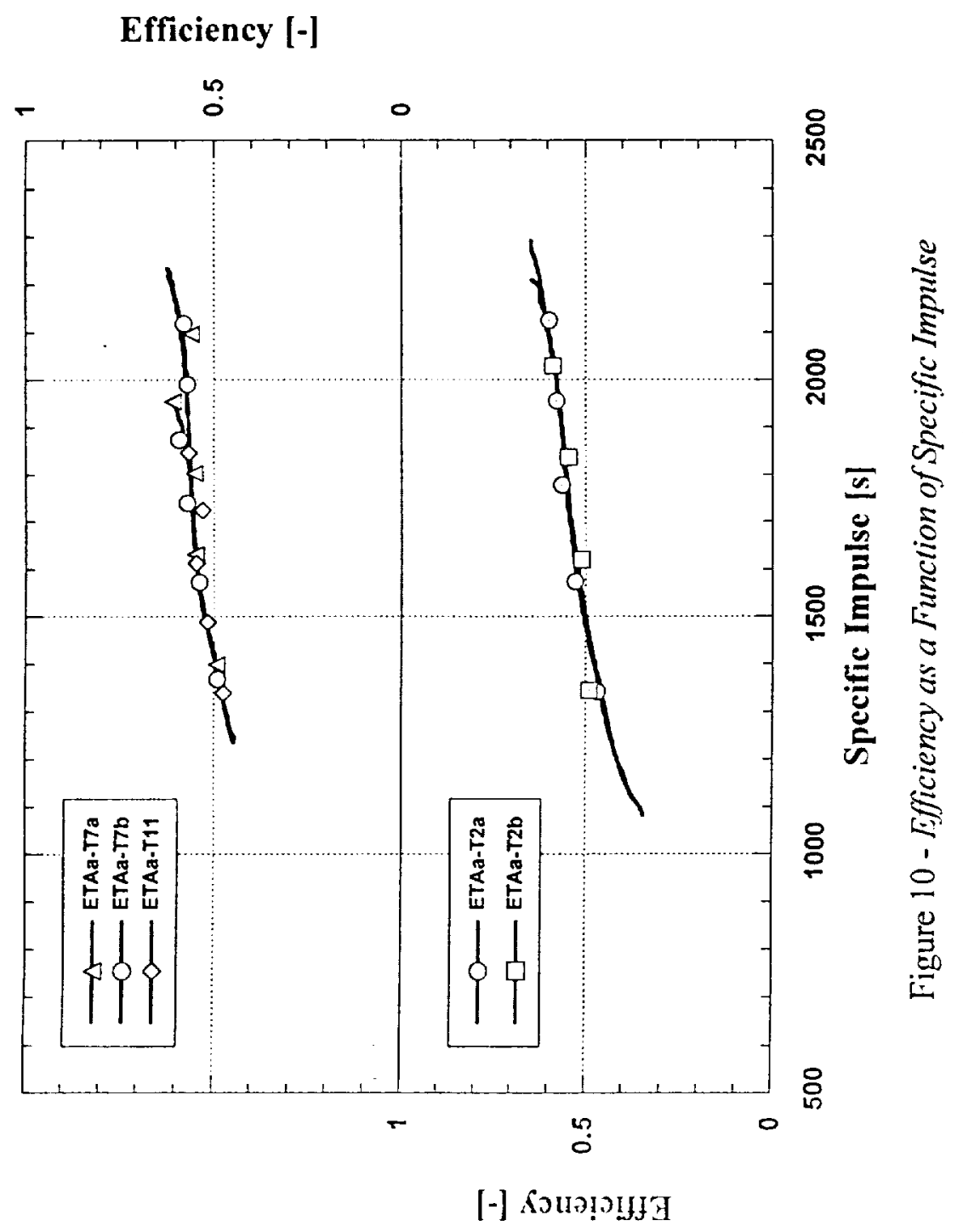




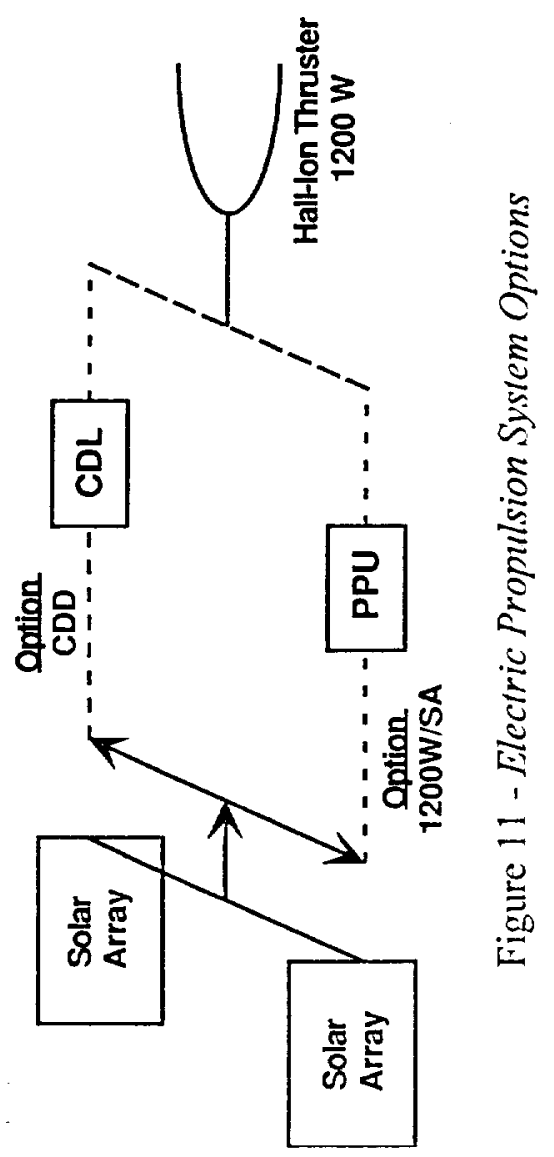




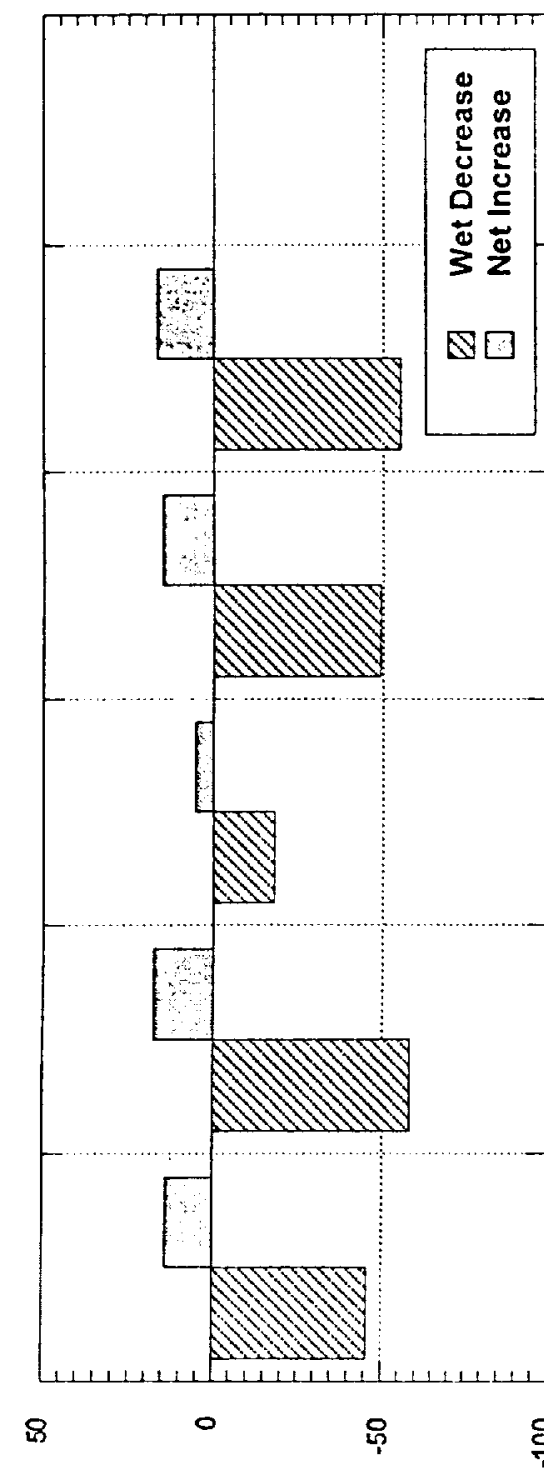

[\%] au!jaseg ol asrajaag/aseajau]
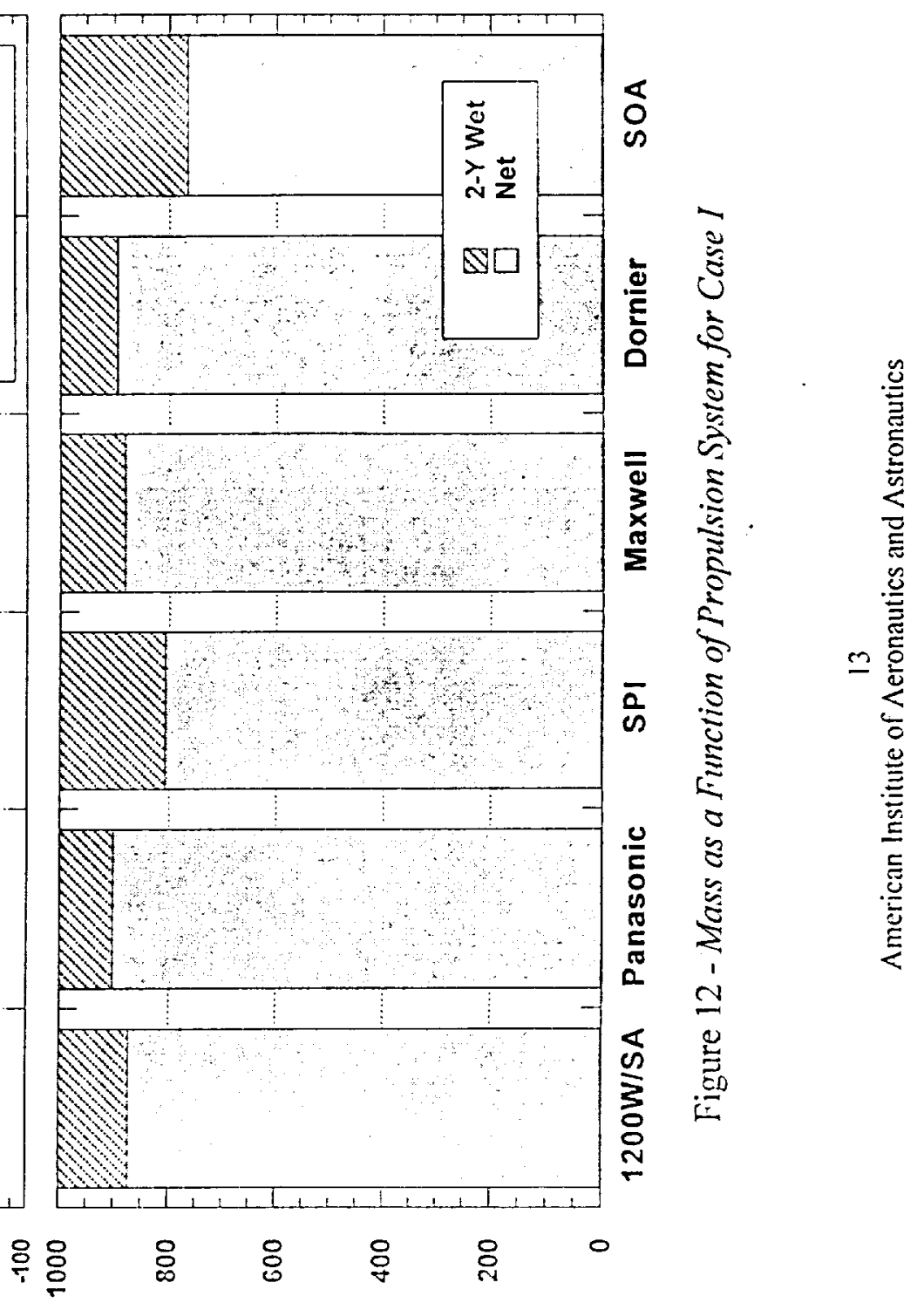

[6y] sseil 


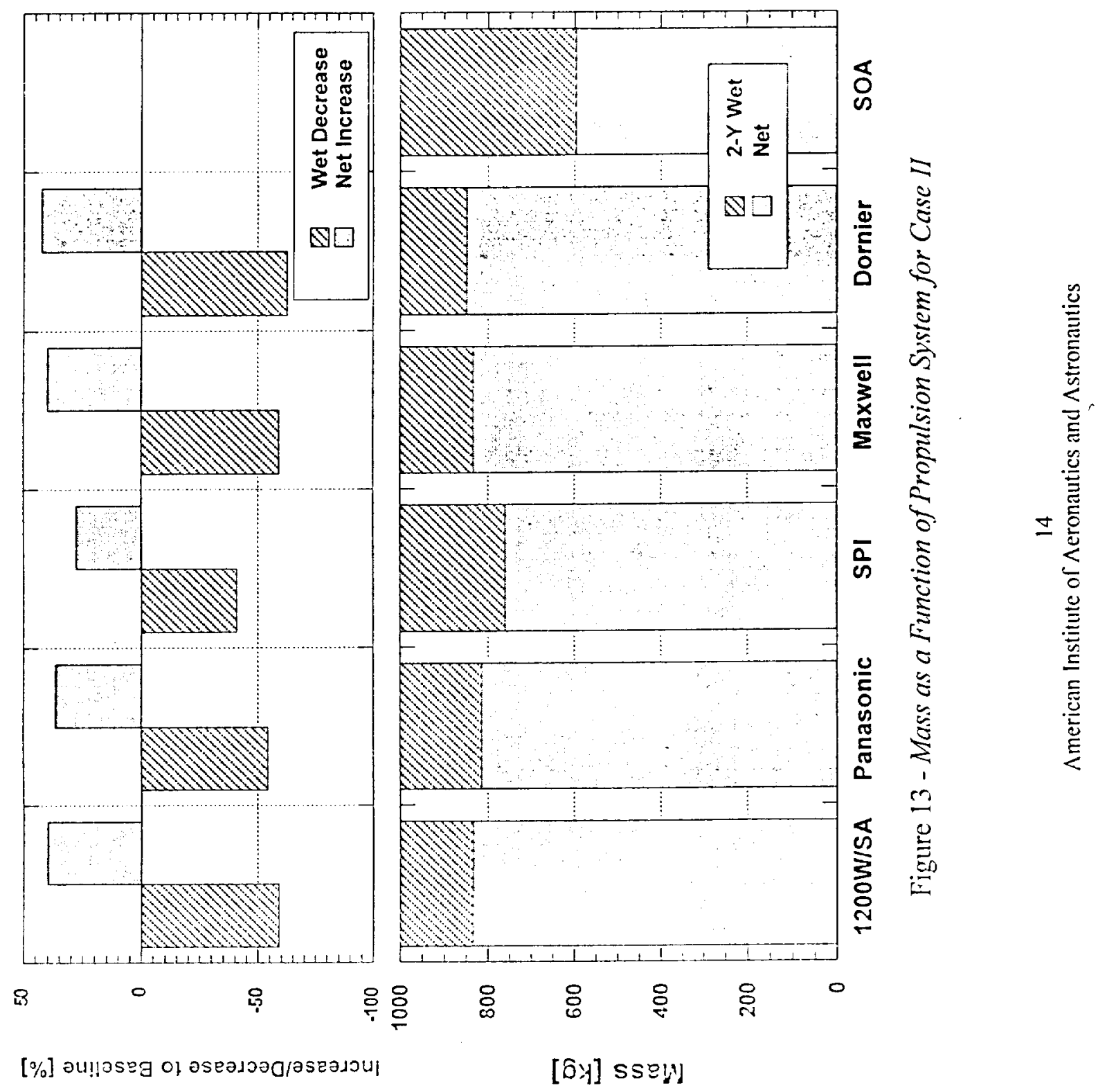




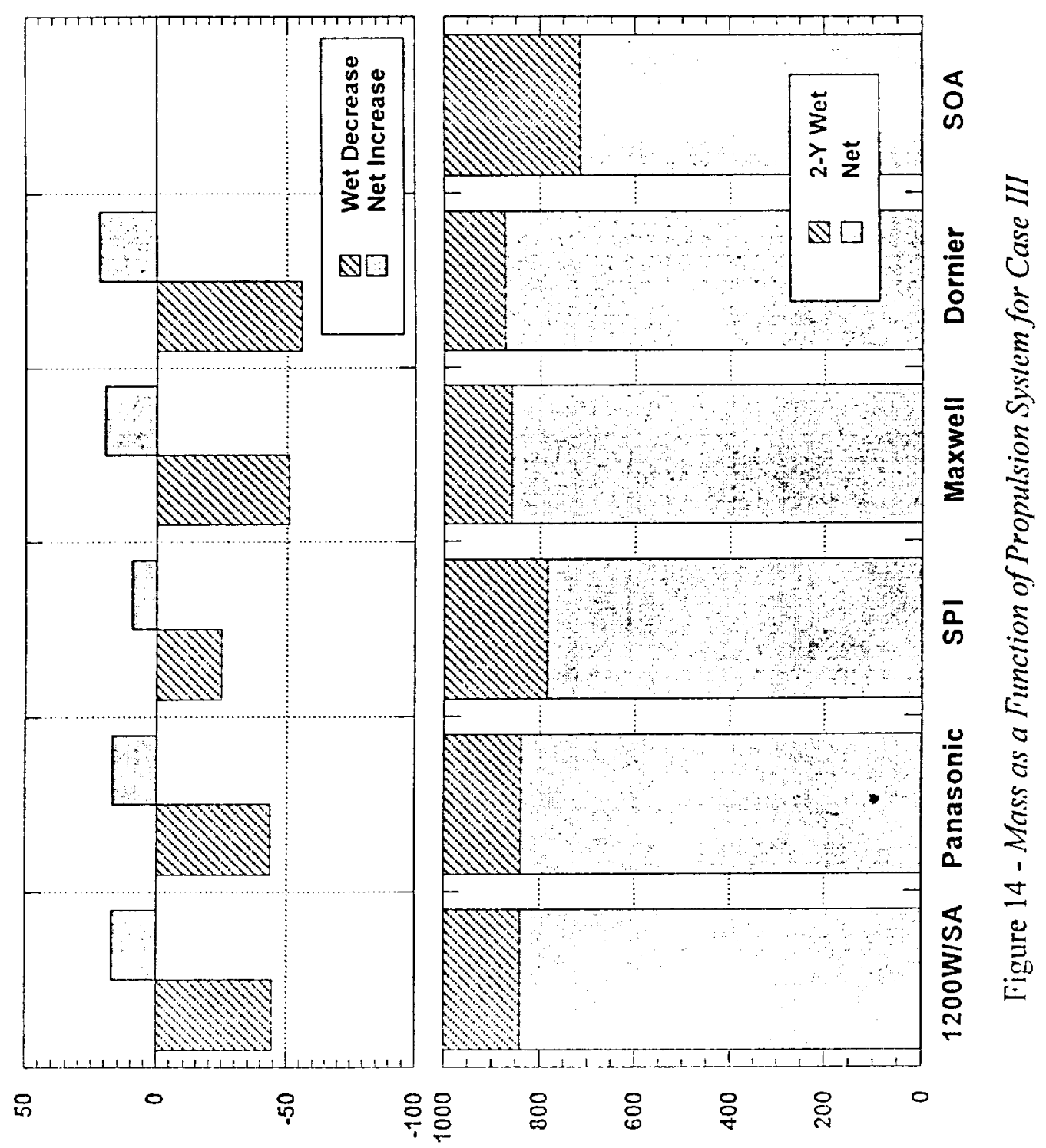

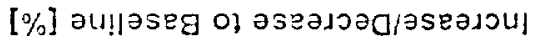

[6ㄱ] sse!n 


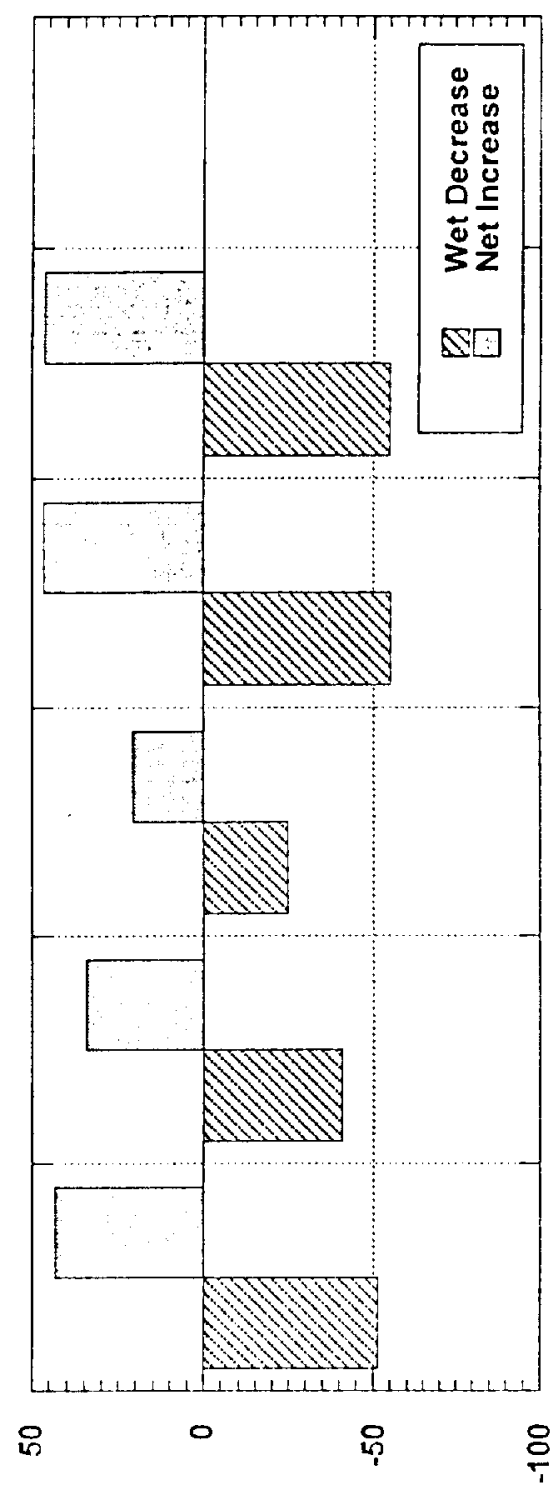

[\%] autiaseg ol ascajoadaseanou

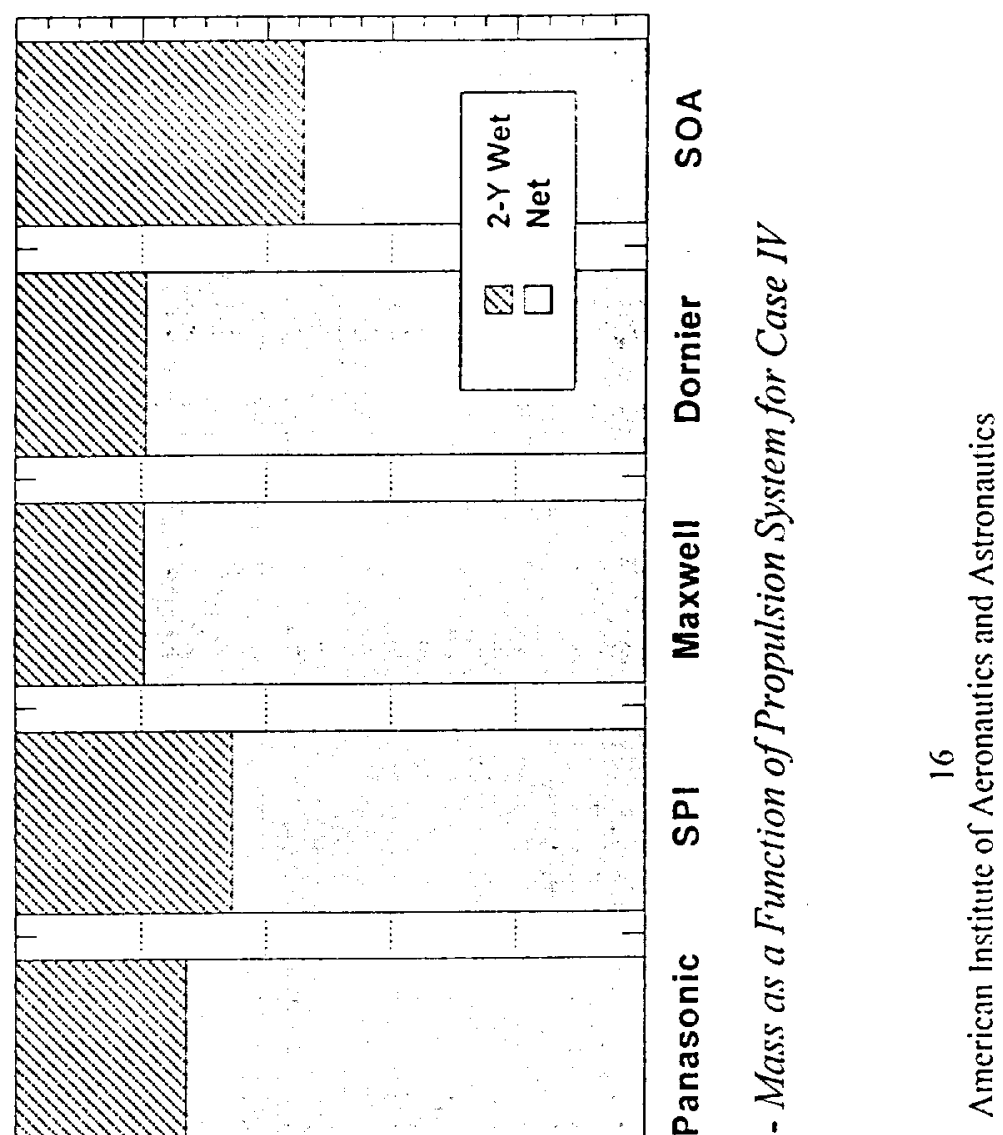

융용 \& 웅

[6x] ssey 


\section{Table of Tables}

Table 1 - Comparison of Available Power Storage Technologies for Space Applications ..............2

Table 2 - Summary of Performance Characteristics .............................................................

Table 3 - Summary of CDL Capacitor Configuration for Mission Analysis ..............................

Table 4 - Summary of Propulsion System Characteristics ..................................................5

Table 5 - Summary of Mission Analysis for Case I: '6am/6pm Sun Synchronous Orbit/Solar Average Atmospheric Density'......................................................6

Table 6 - Summary of Mission Analysis for Case II: '6am/6pm Sun Synchronous Orbit/Solar Maximum Aimospheric Density' ........................................................

Table 7 - Summary of Mission Analysis for Case III: '12am/12pm Sun Synchronous Orbit/Solar Average Atmospheric Density' '..........................................................

Table 8 - Summary of Mission Analysis for Case IV: '12am/12pm Sun Synchronous Orbit/Solar Maximum Atmospheric Density' 


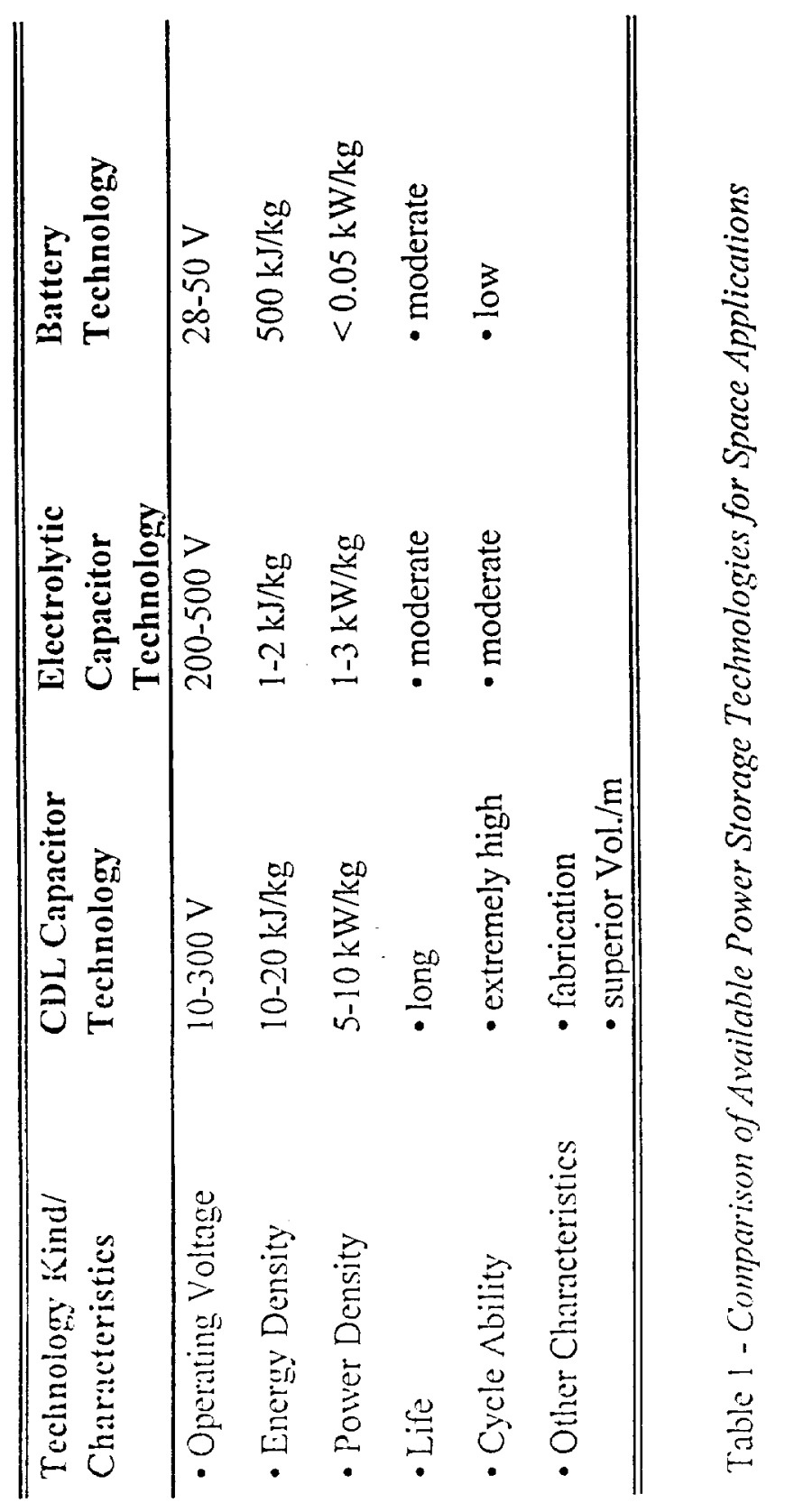




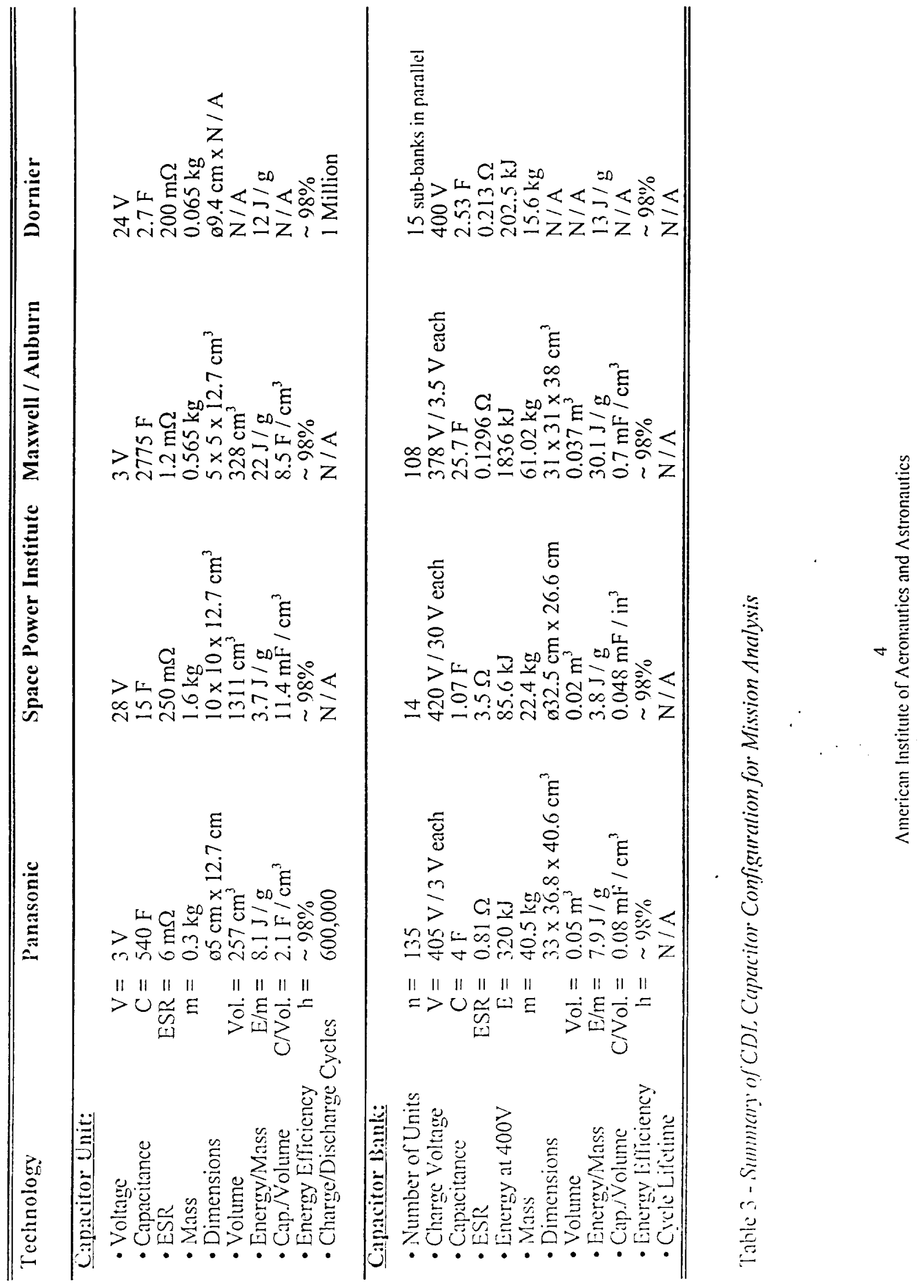




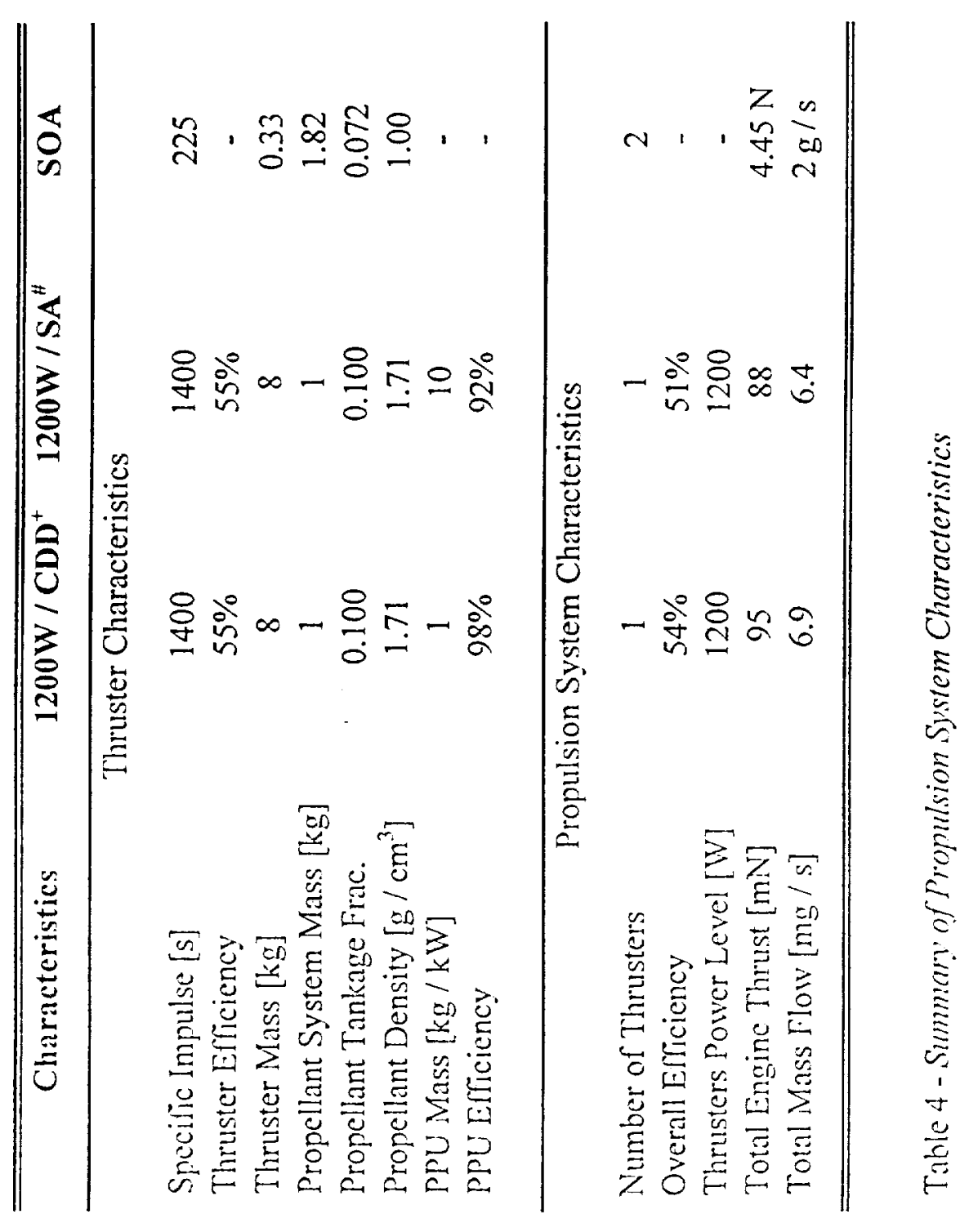

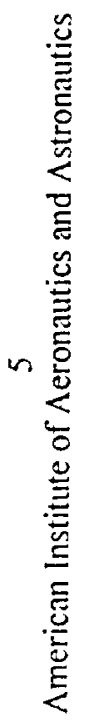




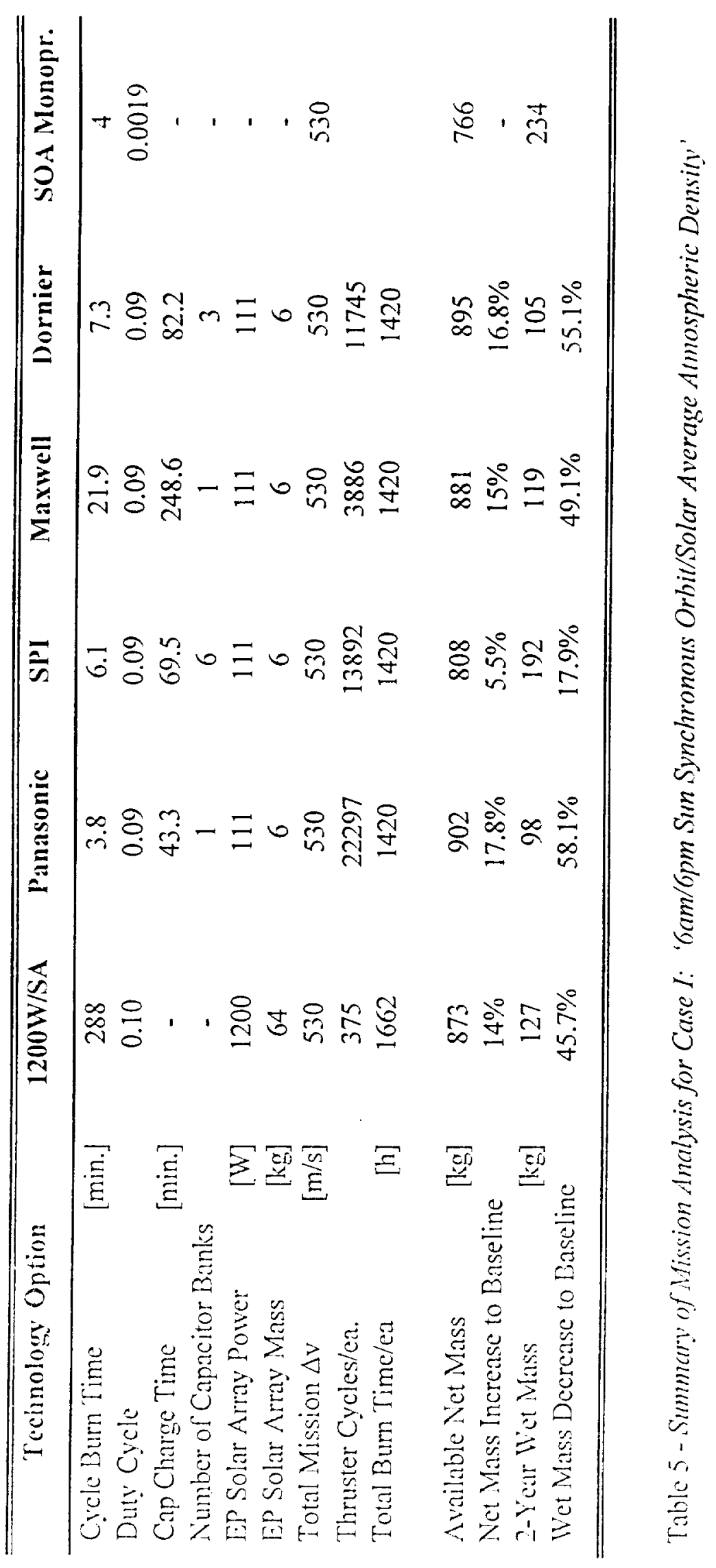




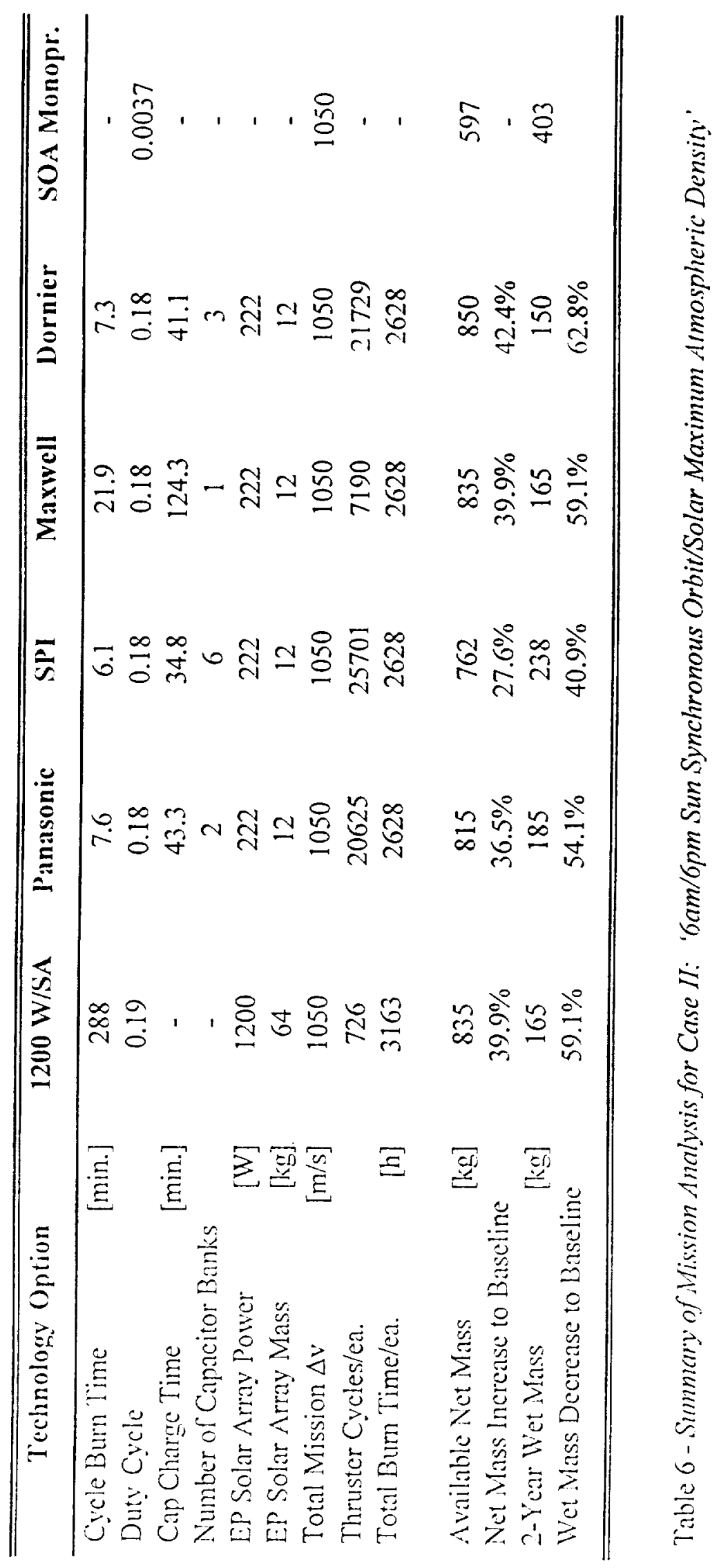




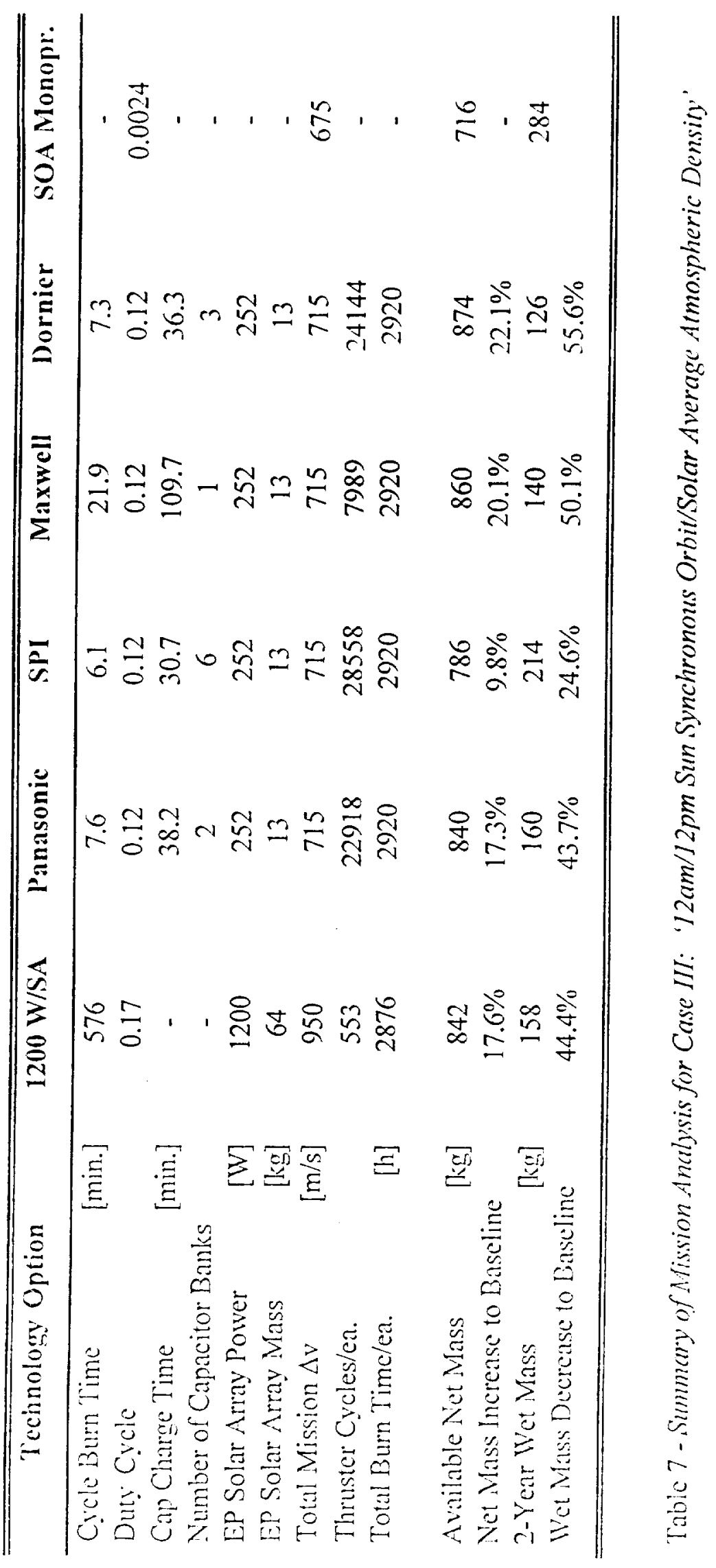




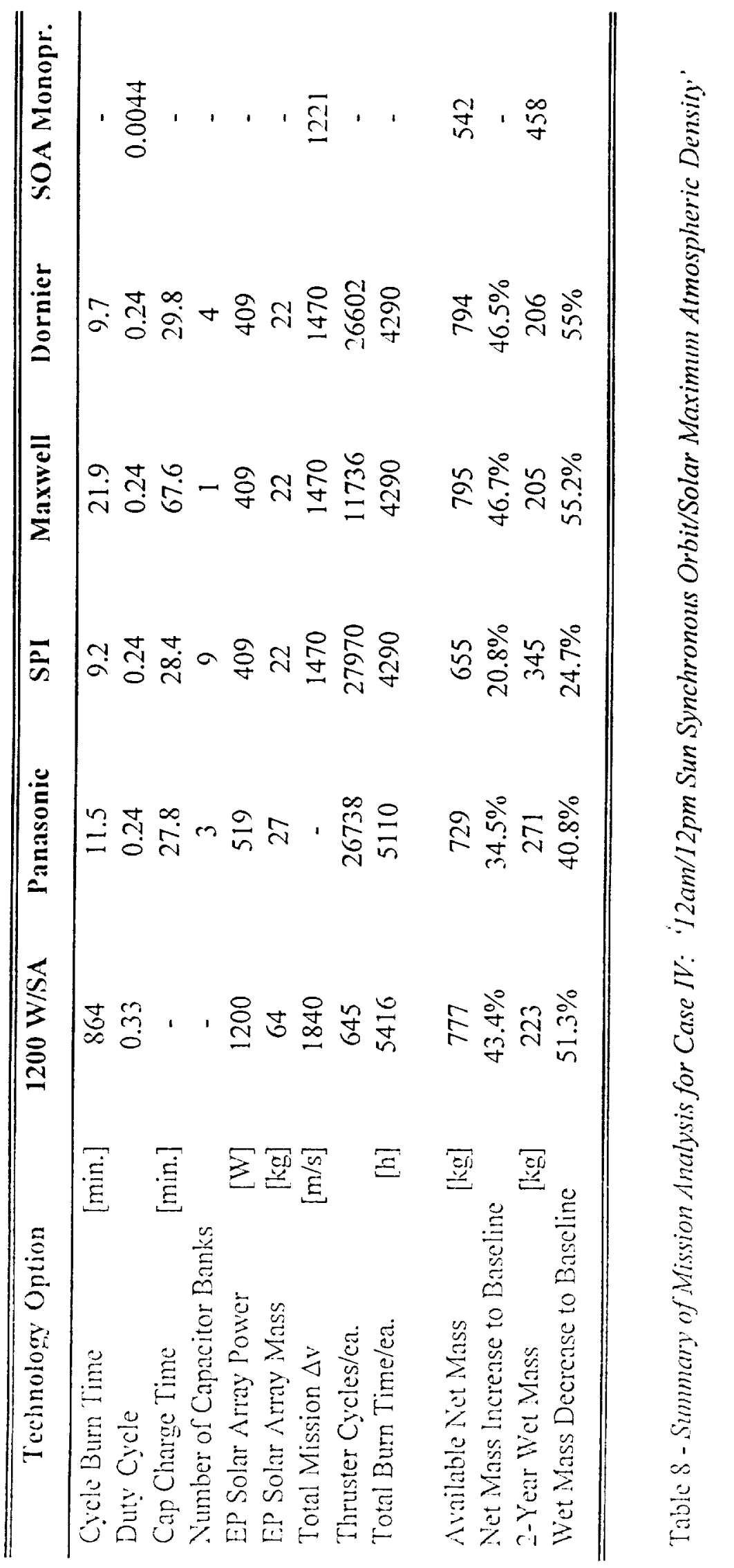

